\title{
Pulmonary CD103+ dendritic cells prime Th2 responses to inhaled allergens
}

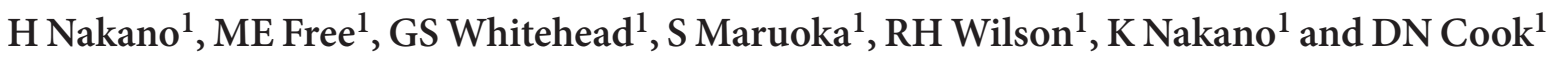

\begin{abstract}
Allergic asthma stems largely from the actions of Thelper 2 (Th2) cells, but the pathways that initiate Th2 responses to inhaled allergens are not fully understood. In the lung, there are two major subsets of dendritic cells (DCs), displaying CD11b or CD103. We found that after taking up inhaled ovalbumin in vivo, purified CD103+ DCs from the lung or lung-draining lymph nodes primed Th2 differentiation ex vivo. Th2 induction by CD103+ DCs was also seen when cockroach or house dust mite allergens were used. In contrast, CD11 bi DCs primed Th1 differentiation. Moreover, mice lacking $\mathrm{CD}_{103^{+}} \mathrm{DC}$ s displayed diminished Th2 priming to various inhaled allergens and did not develop asthma-like responses following subsequent allergen challenge. Low-level antigen presentation by CD103+ DCs was necessary, but not sufficient for Th2 priming. Together, these findings show that $C D 103^{+}$DCs have a significant role in priming Th2 responses to inhaled allergens.
\end{abstract}

\section{INTRODUCTION}

Antigen-presenting cells (APCs) stimulate naive $\mathrm{CD} 4^{+} \mathrm{T}$ cells and direct their differentiation to various T-cell lineages having specialized functions for pathogen clearance. ${ }^{1}$ T helper 1 (Th1) cells provide protective immunity against viruses and intracellular bacteria, whereas Th17 cells promote clearance of extracellular bacteria. ${ }^{2}$ Th2 cells help to clear helminths by promoting immunoglobulin-E production, eosinophil proliferation, and mucus production, but these same responses to Th2 cytokines are pathogenic in the setting of allergic diseases such as asthma. An improved understanding of the APCs and molecules that drive Th2-cell differentiation might provide new opportunities for therapeutic intervention in multiple disease settings.

Naive $\mathrm{CD} 4{ }^{+}$T-cell differentiation into specific T-cell lineages is determined largely by local cytokine levels. Th1 differentiation is driven by interleukin (IL)-12, which is produced in very high amounts by monocyte-derived, $\mathrm{Ly}_{6} \mathrm{C}^{+} \mathrm{CD} 11 \mathrm{~b}^{+}$inflammatory dendritic cells (DCs). ${ }^{3,4}$ Th17-cell differentiation is directed by transforming growth factor- $\beta$ together with either IL- 6 or IL- $1,{ }^{5}$ whereas transforming growth factor- $\beta$ on its own or together with retinoic acid promotes the differentiation of regulatory T cells. ${ }^{6}$ Unlike these relatively well-characterized mechanisms, the cells and molecules that promote Th2 differentiation remain poorly understood. Although IL-4 can promote Th2 differentiation in vitro by activating STAT6 and promoting GATA3 expression, DCs do not produce IL-4. ${ }^{7,8}$ Accordingly, identifying the
APC and cellular source of IL- 4 that directs Th2 differentiation in vivo has been the focus of considerable effort during the past several years. It was recently proposed that basophils are both necessary and sufficient for inducing Th2 responses in vivo. This suggestion arose from the findings that basophils can produce IL-4 and present antigen in the context of major histocompatibility complex (MHC), and that antibodies directed against the basophil-expressed high-affinity immunoglobulin-E receptor (FcERI $\alpha$ ) can suppress Th2 responses in mice. ${ }^{9-12}$ However, subsequent studies showed that genetically engineered mice lacking basophils are nonetheless able to initiate Th2-cell differentiation, including allergic pulmonary inflammation, ${ }^{13,14}$ and several recent studies have shown a requirement of DCs for Th2 induction. ${ }^{13-16}$ It was recently reported that anti-Fc\&RI $\alpha$ antibodies diminish Th2 responses by depleting a subset of DCs in lungdraining lymph nodes (LNs) that display this receptor. ${ }^{15}$ Although FcERI $\alpha$-displaying DCs were shown to prime allergic responses, it is unclear if these DCs are unique in this regard, or if other DCs in the lung and draining LNs possess similar activities.

CD $11 \mathrm{c}^{+}$DCs residing in the lung and draining LNs can be divided into two major subsets, based on their display levels of the CD11b and $\alpha_{E}(C D 103) \beta_{7}$ integrins. ${ }^{17}$ Lung-resident $\mathrm{CD} 11 \mathrm{~b}^{\text {hi }}$ DCs reside beneath the pulmonary epithelium, produce high levels of chemokines ex vivo, and can sustain allergic pulmonary inflammation during the challenge phase of allergic responses. ${ }^{18,19} \mathrm{CD} 103^{+}$DCs are more closely associated with

\footnotetext{
${ }^{1}$ Laboratory of Respiratory Biology, Division of Intramural Research, National Institute of Environmental Health Sciences, NIH, Research Triangle Park, North Carolina, USA. Correspondence: DN Cook (cookd@niehs.nih.gov) 
the airway epithelium and express langerin. ${ }^{17,20}$ Although these two lung DC subsets were previously reported to have similar T-helper-inducing activities after exogenous peptide loading ex vivo, ${ }^{18}$ this procedure bypasses events related to in vivo uptake of inhaled antigens. In the present study, we instilled allergen directly into the airway to allow lung-resident DCs to take up the allergen in vivo. The abilities of the two major lung DC subsets to prime Th2 differentiation of naive $\mathrm{T}$ cells were then assessed by coculture with naive $\mathrm{CD} 4^{+} \mathrm{T}$ cells. In these studies, $\mathrm{CD} 103^{+}$ DCs could prime Th2 differentiation, whereas CD11b ${ }^{\text {hi }}$ DCs primed Th1 differentiation. Moreover, mice lacking $\mathrm{CD} 103^{+}$ DCs had dramatically reduced allergic responses to clinically relevant allergens, including cockroach antigens (CAs) and house dust extracts (HDEs).

\section{RESULTS}

\section{Selective priming of Th2 differentiation by $\mathrm{CD} 103^{+} \mathrm{DCs}$}

Allergic sensitization through the airway can be achieved by airway instillation of chicken ovalbumin (OVA) together with low doses of lipopolysaccharide (OVA-LPS). ${ }^{21-23}$ To investigate lung DC function during allergic sensitization, we first confirmed that both major DC subsets can take up inhaled antigens. Alexa Fluor-647 dye-labeled OVA was instilled into the airways, and DCs in the lung and LNs were analyzed by flow cytometry $16 \mathrm{~h}$ later (Figure 1a and $\mathbf{b}$ ). As expected, nonautofluorescent $\mathrm{CD} 11 \mathrm{c}^{\text {hi }}$ conventional DCs were comprised of two major subsets, CD11 b ${ }^{\text {hi }}$ and CD103+ DCs. Although alveolar macrophages also display CD11c, they are autofluorescent, which allows them to be distinguished from DCs. ${ }^{24}$ In the lung, the frequency of OVA-positive cells and the intensity of OVA signals were higher for CD1 $1 b^{\text {hi }}$ DCs than for CD103+ DCs (Figure 1c). Interestingly, the converse was true in draining LNs (Figure 1d), in agreement with a previous report. ${ }^{25}$ Thus, lung CD11 b ${ }^{\text {hi }}$ DCs can take up more OVA, but OVA-bearing CD103 ${ }^{+}$ DCs might migrate more efficiently to LN than do CD $11 b^{\text {hi }}$ DCs. Nonetheless, these results indicate that substantial number of CD11b $\mathrm{b}^{\text {hi }}$ and $\mathrm{CD} 103^{+}$DCs can acquire inhaled antigens.

To test the ability of lung DCs to stimulate naive $\mathrm{CD} 4^{+} \mathrm{T}$ cells, we purified CD1 $1 \mathrm{~b}^{\text {hi }}$ DCs and CD103 ${ }^{+}$DCs from the lungs of C57BL/6 mice that had received OVA-LPS. A novel cocktail of enzymes was used to obtain higher yields of purified DCs than that has been previously achieved using widely used enzymes (Figure 1e). Analysis of the sorted cell populations by analytical flow cytometry and by microscopy revealed that each population was highly pure and comprised almost entirely of DCs (Figure 1f). To assess the ability of these two DC subsets to induce T-cell proliferation, they were separately cocultured with 5,6-carboxyfluorescein diacetate succinimidyl ester (CFSE)-labeled naive CD4 ${ }^{+}$ $\mathrm{T}$ cells purified from OVA-specific T-cell receptor transgenic OT-II mice. Both DC subsets induced T-cell proliferation as determined by dilution of the CFSE label in the dividing cells, with $\mathrm{CD}_{103^{+}}$ DCs being slightly more efficient in this regard (Figure $\mathbf{~} g$ and $\mathbf{h}$ ). These findings were confirmed by T-cell counts after the 5-day culture (Supplementary Figure S1a online).

To determine whether the two major lung DC subsets differed in their ability to promote naive T-cell differentiation to helper
T cells, we first assessed intracellular levels of signature cytokines in $\mathrm{T}$ cells after cocultures. Flow cytometric analyses of these cells revealed that there were more interferon (IFN)- $\gamma^{+} \mathrm{T}$ cells in cocultures containing CD $11 b^{\text {hi }}$ DCs, whereas IL- $4^{+}$and IL- $13^{+}$ $\mathrm{T}$ cells were more abundant in cocultures containing $\mathrm{CD} 103^{+} \mathrm{DCs}$ (Figure 2a and $\mathbf{b}$ ). Analysis of cytokines in the supernatants of these cells confirmed that T-cell production of IFN- $\gamma$ production was preferentially induced by CD $11 b^{\text {hi }} \mathrm{DCs}$, and that production of IL- 5 and IL- 13 was induced by CD103 ${ }^{+}$DCs, although IL- 4 levels were low in both conditions (Supplementary Figure S1b online). To further test the induction of Th2 cells by $\mathrm{CD} 103^{+}$ DCs, we cultured lung DCs from BALB/c mice together with naive $\mathrm{CD} 4{ }^{+} \mathrm{T}$ cells from OVA-specific DO11.10 T-cell receptor transgenic IL-4-GFP reporter (4get) mice. IL-4-GFP ${ }^{+}$cells were more abundant after culture with $\mathrm{CD}_{103}{ }^{+} \mathrm{DCs}$ than after culture with CD11b $b^{\text {hi }}$ DCs (Figure $2 \mathbf{c}$ and $\mathbf{d}$ ), confirming that the former DC subset is more effective at promoting Th2 differentiation. Cytokine levels in supernatants of primary DC-T-cell cocultures can be affected by multiple factors, including DCderived cytokines, T-cell proliferation, and cytokine internalization. For these reasons, cytokine production from differentiated $\mathrm{T}$ cells is frequently elicited by short-term restimulation. ${ }^{26} \mathrm{After}$ incubation in plate-bound anti-CD $3 \varepsilon$ and -CD28 antibodies, $\mathrm{CD} 4^{+} \mathrm{T}$ cells that had been cultured with $\mathrm{CD} 103^{+}$lung DCs produced high levels of IL-4, IL-5, and IL-13, but only low levels of IFN- $\gamma$ (Figure 2e). Conversely, T cells that had been cocultured with CD11b $\mathrm{b}^{\text {hi }}$ DCs produced high levels of IFN- $\gamma$, but only low levels of IL-4, IL-5, and IL-13. Lung CD $103^{+}$DCs, but not CD11bi DCs, also stimulated low-level production of the Th17 signature cytokine, IL-17. Similar results were obtained whether OT-II CD4 ${ }^{+}$T cells or Rag2 ${ }^{-/-}$OT-II CD4 ${ }^{+} \mathrm{T}$ cells were used. The selective ability of the lung $\mathrm{CD} 103^{+} \mathrm{DCs}$ to prime Th2 responses was not a unique feature of $\mathrm{C} 57 \mathrm{BL} / 6$ mice because similar findings were seen when DCs from BALB/c mice were used (Supplementary Figure S2 online). The Th2 stimulatory activity of $\mathrm{CD} 103^{+}$lung DCs was also not caused by the enzymatic digestion of lung tissue, because although the recovery of DCs from the lung was greatly reduced when no enzymes were used in the preparation, the recovered $\mathrm{CD} 103^{+}$ DCs also induced T-cell proliferation and Th2 differentiation (Supplementary Figure S3 online).

Lung-draining mediastinal LN DCs were similarly tested for their ability to promote Th2 differentiation. Both CD11b ${ }^{\text {hi }}$ DCs and $\mathrm{CD}_{103}{ }^{+} \mathrm{DCs}$ from LNs were able to stimulate robust proliferation of T cells (data not shown). LN CD103 ${ }^{+}$DCs also selectively and potently stimulated $\mathrm{Th} 2$ differentiation as determined by the production of IL-4, IL-5, and IL-13, whereas the CD $11 b^{\text {hi }}$ subset selectively primed Th1 differentiation (Figure 2ff). Unlike CD103 ${ }^{+}$DCs derived from the lung, neither DC subset prepared from LNs induced IL-17 production.

\section{CD103+ DCs prime Th2 differentiation to inhaled clinically relevant allergens}

Although OVA is frequently used in studies of T-cell differentiation and allergic pulmonary inflammation, it is not a clinically relevant allergen. To study pulmonary DC uptake of environmental 

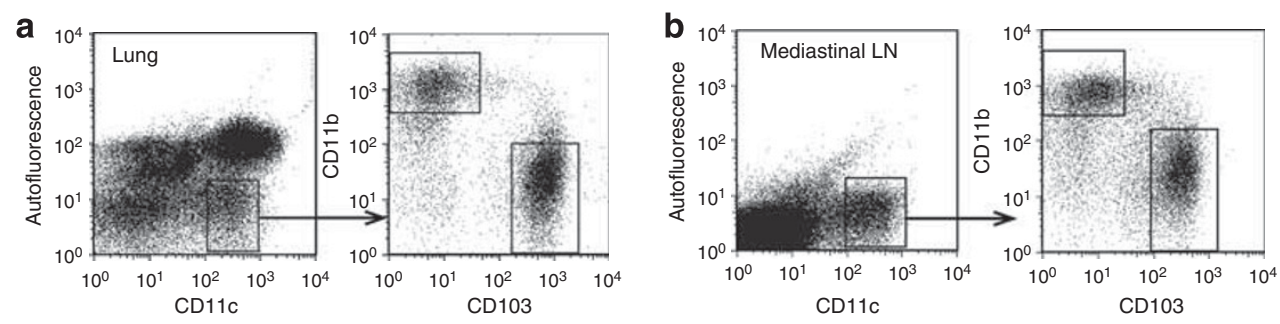

C
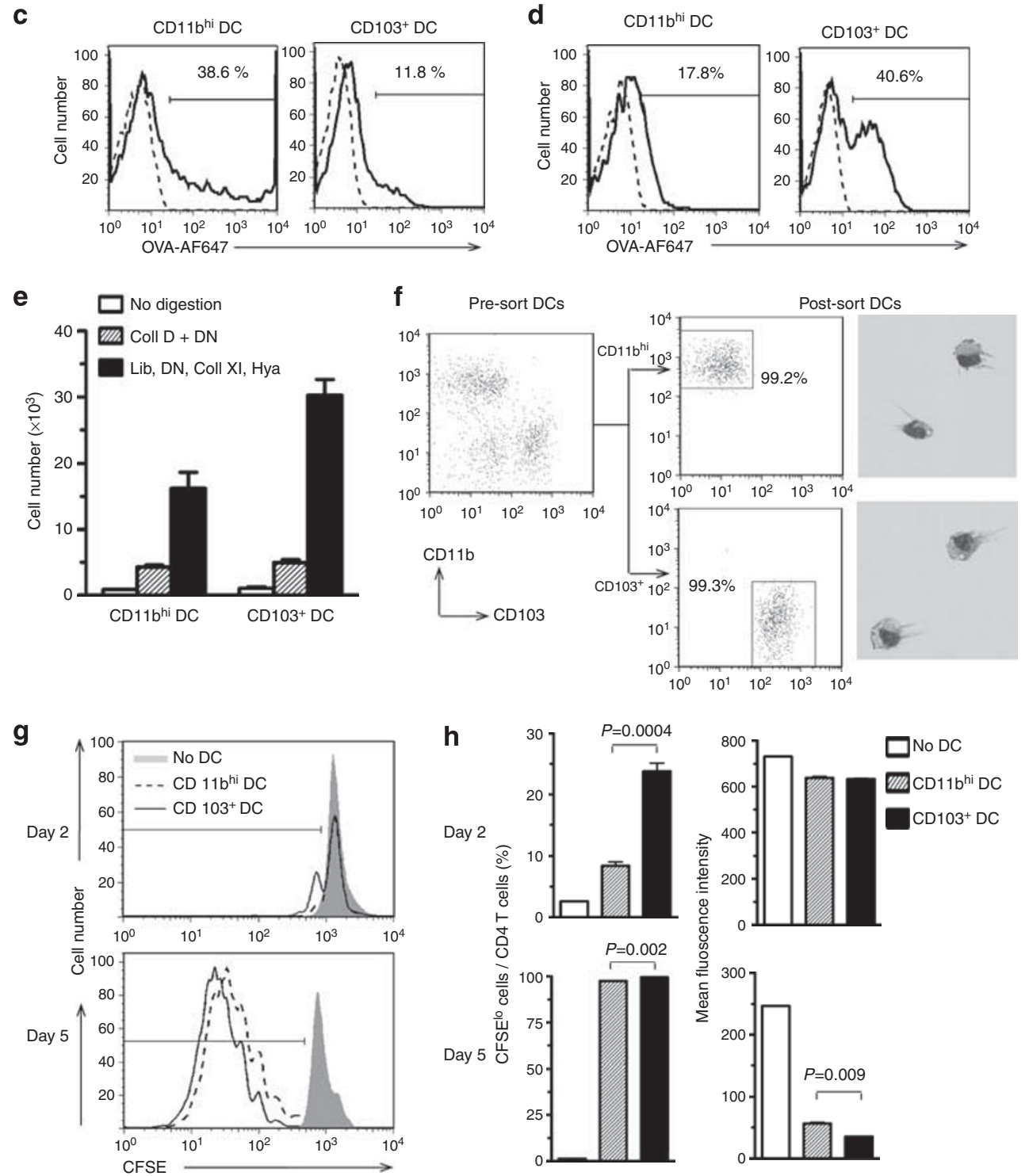

Figure 1 Uptake of inhaled antigen and naive T-cell stimulation by CD11 bi dendritic cells (DCs) and CD103+ DCs. (a, b) Flow cytometric gating for non-autofluorescent, CD11 $\mathrm{c}^{\text {hi }}$ DCs from lungs (a) and mediastinal lymph nodes (LNs; b) of C57BL/6 mice. (c, d) Ovalbumin (OVA) uptake by DC subsets from the lung (c) and mediastinal LNs (d) from untreated mice (dashed line) or from mice instilled with $100 \mu \mathrm{g}$ Alexa Fluor (AF)-647-labeled OVA (OVA-AF647) together with lipopolysaccharide (LPS; solid line). A representative result of two independent experiments is shown. (e) Effect of enzymatic digest on lung DC recovery. Minced lung tissue was incubated with no enzymes (open column), or with enzymes; collagenase (Coll) D, DNase I (DN), Liberase (Lib), Coll XI and hyaluronidase (Hya; $n=5)$. (f) Purity of sorted lung CD11 b ${ }^{\text {hi }}$ DCs and CD103+ DCs. Representative images of each population are shown. (g, h) T-cell proliferation. (g) 5,6-Carboxyfluorescein diacetate succinimidyl ester (CFSE)-labeled, naive CD4+ OT-II T cells were cultured with the indicated DC subsets from OVA-LPS-treated mice and dilution of the CFSE signal assessed by flow cytometry. (h) Percent of CFSE ${ }^{l o}$ cells among CD4T cells and mean fluorescence intensity of CFSE. P-values by Student's $t$-test $(n=3)$.

allergens, cockroach antigen (CA) and house dust mite (HDM) were labeled with Alexa Fluor-647 and separately instilled into airways of mice. Flow cytometric analyses revealed that both
DC subsets in the lung could take up these allergens, although CD $11 b^{\text {hi }}$ DCs took up slightly higher levels (Figure 3a). In mediastinal LNs, the frequency of CA-bearing DCs was 
a
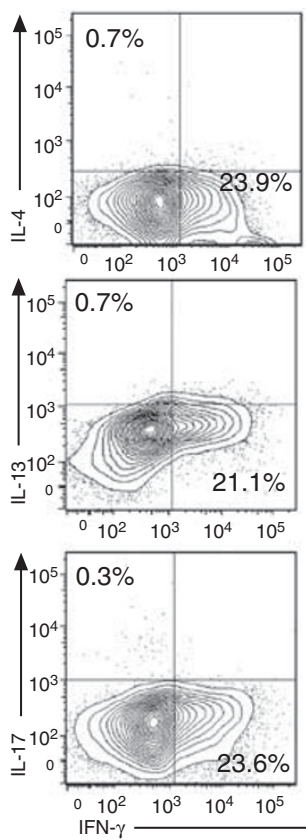

C
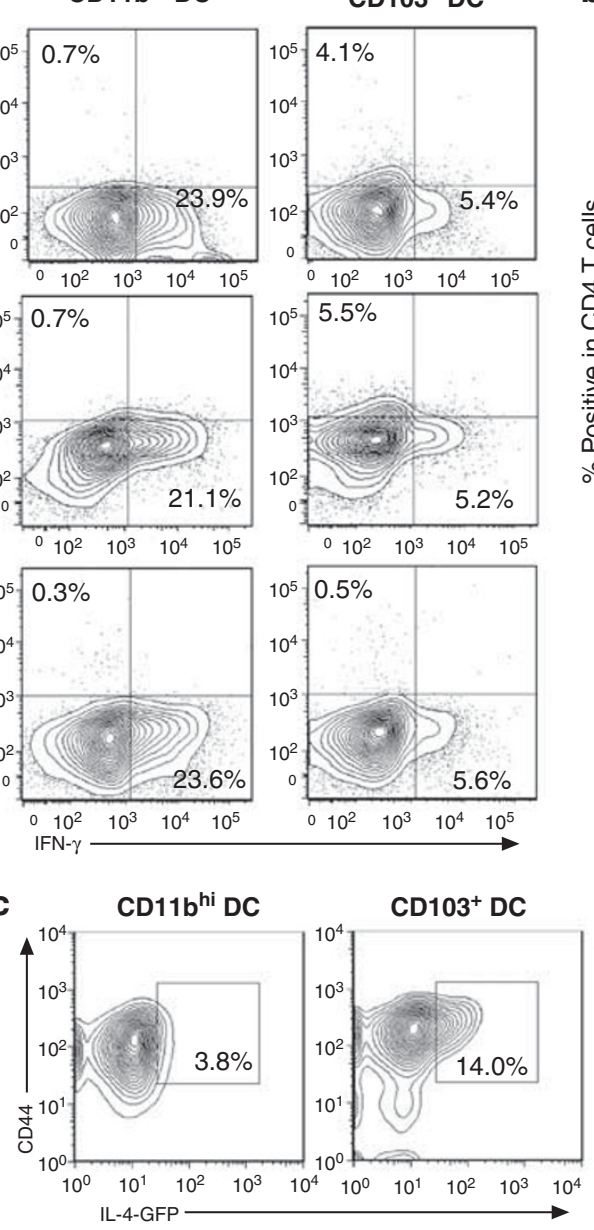

b

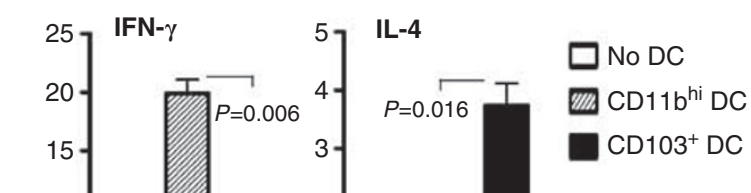

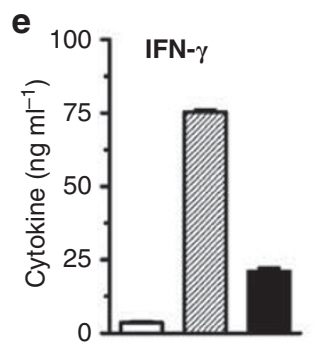
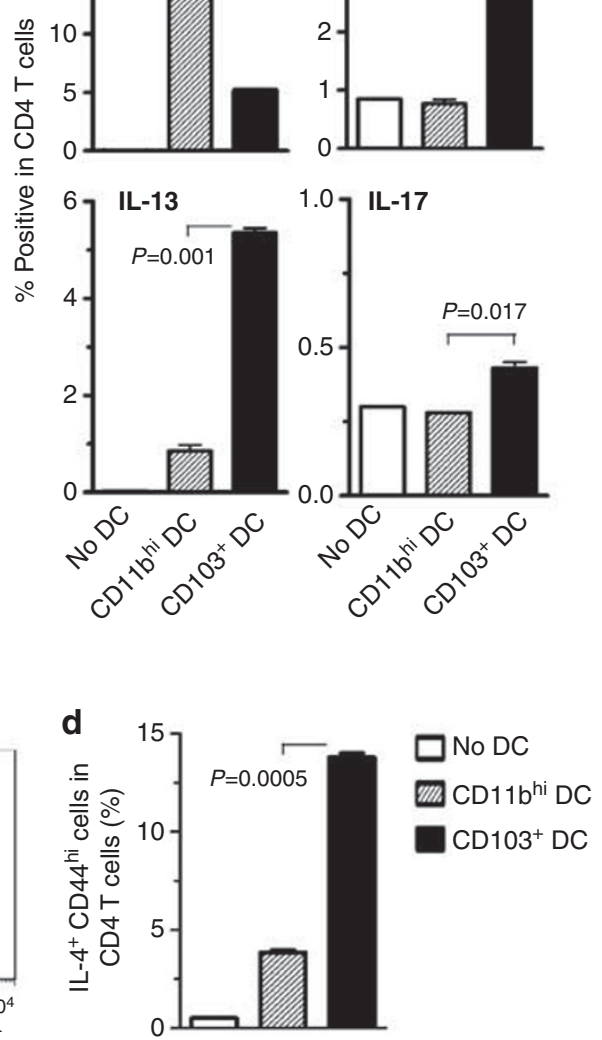

CD103+ DC
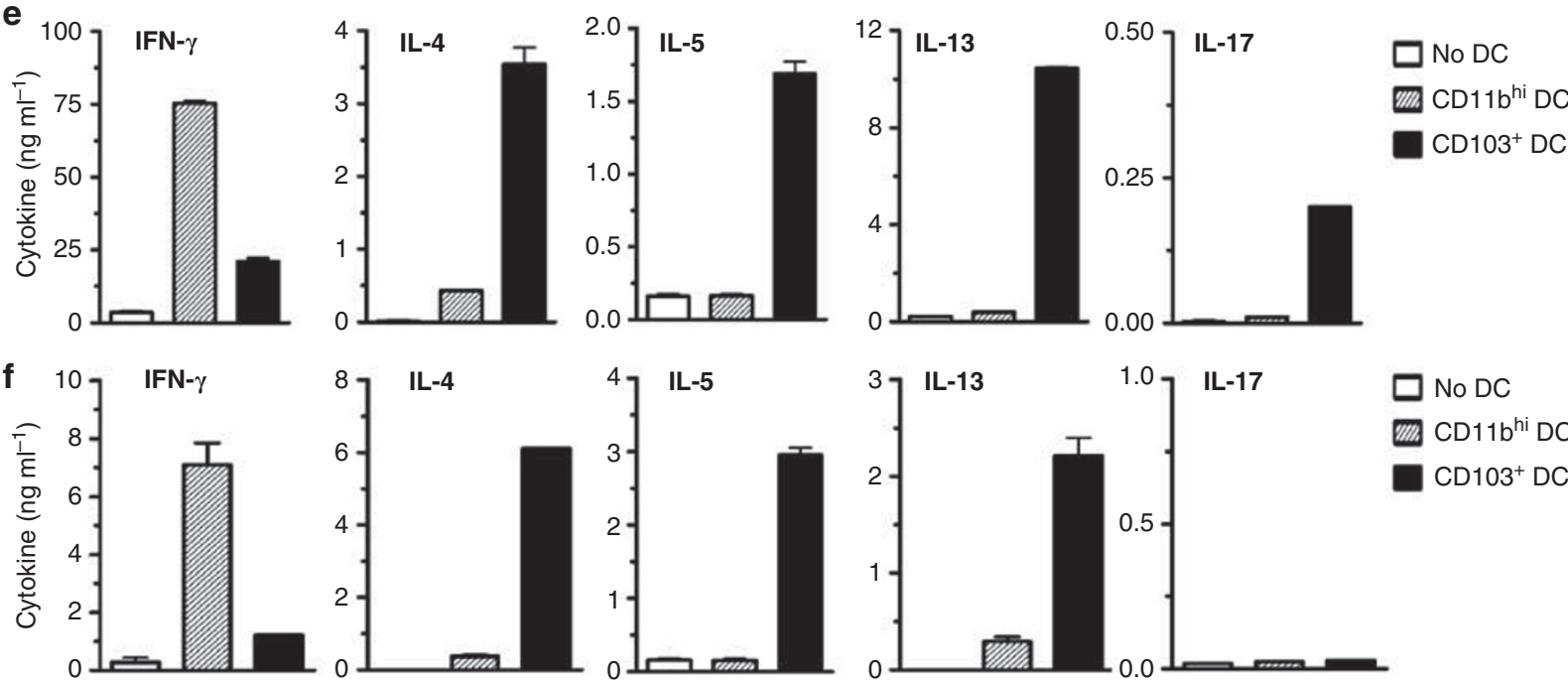

CD103+ DC

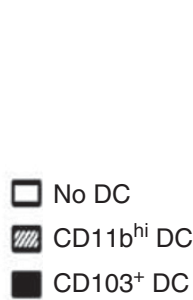

Figure $2 \mathrm{CD} 103^{+}$dendritic cells (DCs) promote Th2 differentiation of naive CD4+ $\mathrm{T}$ cells. (a, b) DCs prepared from the lungs of C57BL/6 mice treated with ovalbumin together with lipopolysaccharide (OVA-LPS) were cocultured with naive CD4 ${ }^{+}$T cells from rag-2 $2^{-/-}$OT-II mice. Intracellular cytokines in CD4 ${ }^{+} \mathrm{T}$ cells were analyzed after 6 days of coculture. Percent of cytokine positive CD4 T cells are indicated in contour plots (a) and histograms of compiled data (b). Data shown represent one of three similar experiments; $P$-values by Student's $t$-test. (c, d) DCs prepared from the lungs of BALB/c mice treated with OVA-LPS were cocultured with naive CD4 ${ }^{+}$T cells from interleukin (IL)-4-green fluorescent protein (GFP) DO11.10 mice. Percentage of IL-4-GFP + CD44 hi cells among all CD4 ${ }^{+} \mathrm{T}$ cells after 5 days of coculture are indicated in contour plots (c) and histograms of compiled data (d). (e, f) Cytokine production by DC-stimulated T cells. The indicated lung DC subsets were prepared from the lungs or mediastinal lymph nodes (f) of OVA-LPS-treated mice and cocultured for 5 days with naive Rag2 ${ }^{-/-}$OT-II CD4 ${ }^{+} \mathrm{T}$ cells. Cultured T cells were incubated for $24 \mathrm{~h}$ in anti-CD3 $\varepsilon$ and anti-CD28-coated plates. Cytokines in the supernatants were measured by enzyme-linked immunosorbent assay. Data presented represent one of at least three independent experiments yielding similar results. IFN- $\gamma$, interferon- $\gamma$; IL, interleukin. 
a

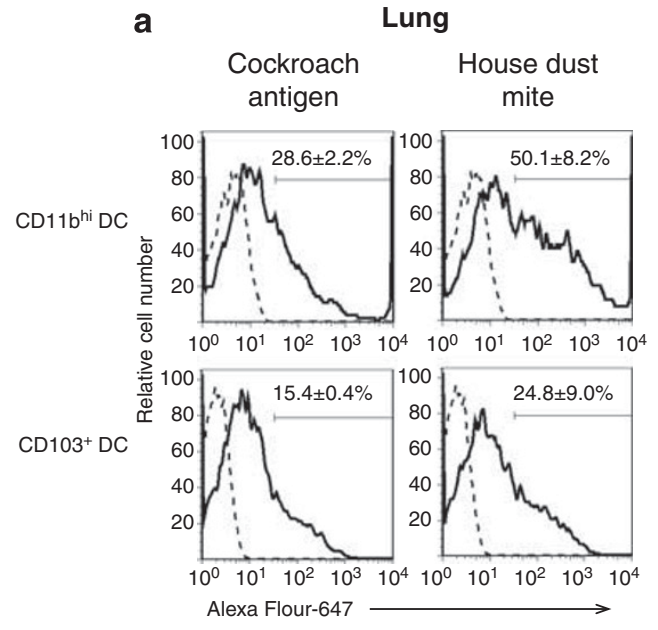

b

b Mediastinal lymph node

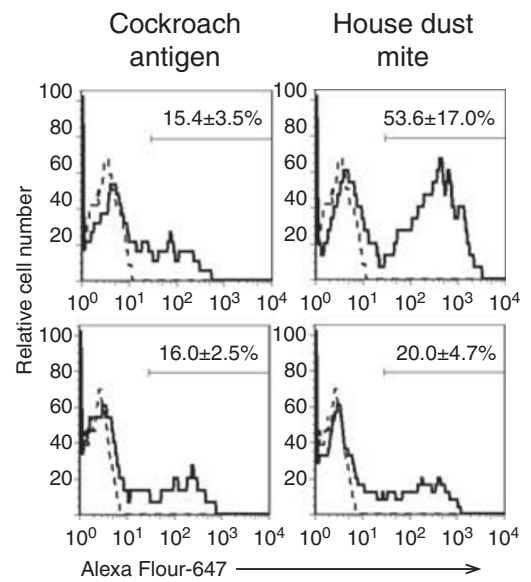

c

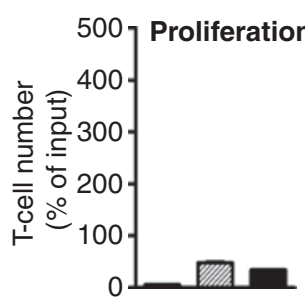

Cockroach antigens

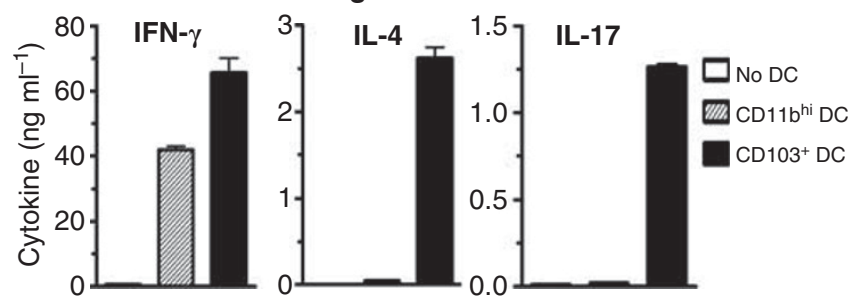

d

House dust mite
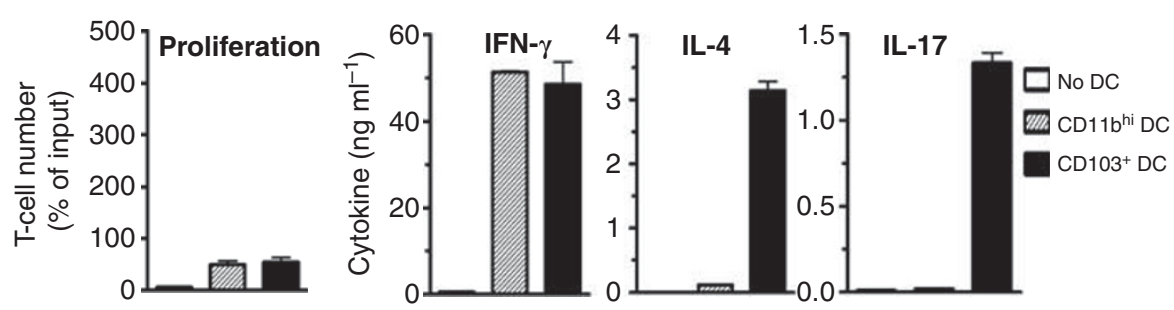

Figure $3 \mathrm{CD} 103^{+}$dendritic cells (DCs) prime Th2 responses to clinically relevant allergens. (a, b) DCs in lung (a) or mediastinal lymph node (b) of untreated C57BL/6 mice (dashed line) or mice that received oropharyngeal aspiration of Alexa Fluor-647-labeled cockroach antigen (CA) or house dust mite (HDM) 16h earlier (solid line). Mean \pm s.e. $(n=3)$ percent antigen-positive DCs are indicated in each histogram. (c, d) Purified lung DCs from C57BL/6 mice receiving CA (c) or HDM (d) were cocultured with naive CD4 ${ }^{+} \mathrm{T}$ cells from C57BL/6 mice. Proliferation of T cells as inferred from T-cell recovery after 5 days of coculture. Cytokines in supernatants of T cells following $24 \mathrm{~h}$ incubation in anti-CD3e- and anti-CD28-coated plates, as measured by enzyme-linked immunosorbent assay. IFN, interferon; IL, interleukin.

comparable between the two subsets, whereas HDM-bearing cells were more frequent among CD11b ${ }^{\text {hi }}$ DCs (Figure $3 \mathbf{b}$ ). Thus, although the amount of allergen uptake can vary, both major DC subsets can take up these clinically relevant allergens. To test if $\mathrm{CD}_{103}{ }^{+} \mathrm{DCs}$ also prime $\mathrm{Th} 2$ responses to these allergens, CD $11 \mathrm{~b}^{\text {hi }}$ and $\mathrm{CD} 103^{+}$DCs were purified from the lungs of CA- or HDM-treated mice and cultured with naive $\mathrm{CD} 4^{+}$ $\mathrm{T}$ cells from C57BL/6 mice. As expected, the magnitude of T-cell proliferation was less than that previously seen for OT-II T cells following OVA presentation by DCs (Figure $3 \mathbf{c}$ and $\mathbf{d}$ ), because only a small number of naive $\mathrm{T}$ cells in untreated C57BL/6 mice would be expected to recognize CA or HDM. However, incubation with anti-CD3e- and CD28 antibodies elicited IL-4 production by $\mathrm{T}$ cells that had been cocultured with $\mathrm{CD} 103^{+} \mathrm{DCs}$ from CA- or HDM-treated mice (Figure $3 \mathbf{c}$ and $\mathbf{d}$ ). Thus, the ability of $\mathrm{CD}_{103}{ }^{+} \mathrm{DCs}$ to prime Th2 responses is not unique to the experimental allergen, OVA, but also extends to clinically relevant allergens. In addition to Th2 priming, CD103 ${ }^{+}$ DCs also primed the differentiation of IL-17-producing T cells in response to CA and HDM. However, in contrast to experiments with OVA, where $\mathrm{CD} 103^{+}$DCs were unable to prime Th1 responses, $\mathrm{CA}$ - and HDM-bearing $\mathrm{CD}_{103}{ }^{+}$DCs could also prime the differentiation of IFN- $\gamma$-producing Th1 cells. To test if microbial components residing in the CA and HDM might enhance the ability of $\mathrm{CD}_{103}{ }^{+}$DCs to promote Th1 differentiation, airways of mice were instilled with OVA together with either LPS or poly I:C, a synthetic analog of double-stranded RNA. CD $103^{+}$DCs prepared from the lungs of OVA-poly I:C (polyinosine-polycytidylic acid)-treated mice promoted higher levels of Th1 differentiation than $\mathrm{CD}_{103}{ }^{+} \mathrm{DCs}$ from OVA-LPStreated mice (Supplementary Figure S4 online). This result is in agreement with a previous report that $\mathrm{CD} 103^{+}$lung DCs 

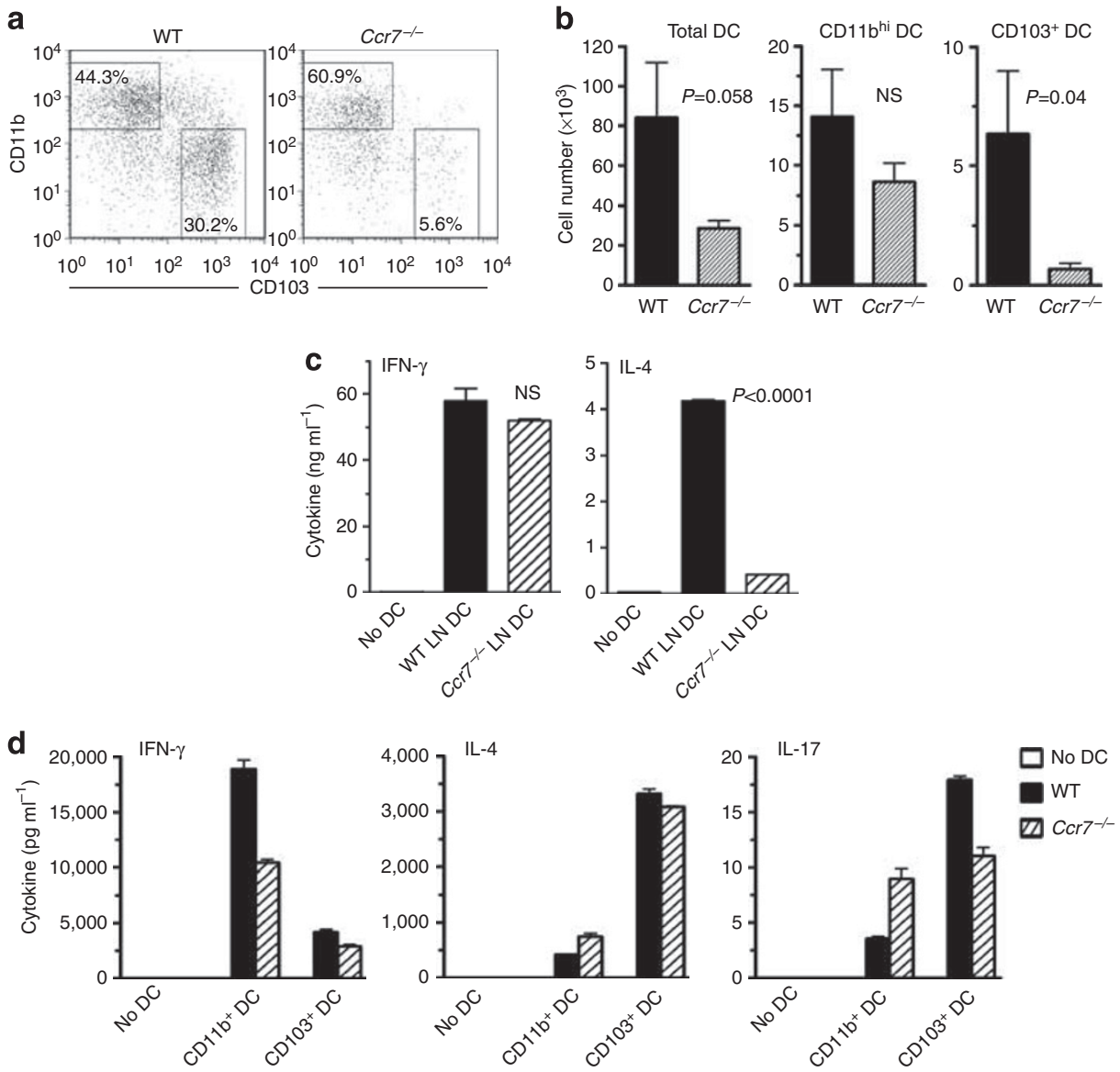

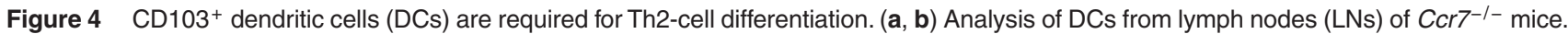
(a) Flow cytometry plots showing percentages of CD11 bi and CD103+ DCs in mediastinal LNs of wild-type (WT) C57BL/6 and Ccr7-/- mice. (b) Histograms showing total DC numbers for each DC subset $(n=5-6)$. Data shown are from one of the two independent experiments giving similar results. (c, d) Induction of T-cell cytokines by total LN DCs (c) or lung-resident DC subsets (d). Naive CD4 ${ }^{+}$OT-II T cells were cultured with the indicated DCs, and cytokine production from T cells was measured by enzyme-linked immunosorbent assay following elicitation by anti-CD3 $\varepsilon$ and CD28 antibodies. $P$-values by Student's $t$-test. IFN, interferon; IL, interleukin; NS, not significant.

prime Th1 differentiation following influenza virus infection. ${ }^{27}$ Thus, depending on the adjuvant used, Th1 differentiation can be primed by either $\mathrm{CD} 103^{+}$DCs or CD11b ${ }^{\text {hi }} \mathrm{DCs}$, whereas Th2 differentiation can be primed only by $\mathrm{CD} 103^{+}$DCs.

\section{Requirement of CD103+ DCs for Th2 differentiation}

Our data thus far had shown that purified $\mathrm{CD} 103^{+}$DCs have a greater capacity to prime $\mathrm{Th} 2$ differentiation of naive $\mathrm{T}$ cells than do CD11 bhi DCs. To confirm this, we tested T-cell stimulation by lung-draining, mediastinal LN DCs of $\mathrm{Ccr}^{-/-}$mice, which were previously shown to contain very few $\mathrm{CD} 103^{+} \mathrm{DCs}{ }^{28} \mathrm{We}$ reasoned that if $\mathrm{CD}_{103}{ }^{+} \mathrm{DCs}$ are required for Th2 priming, total DCs derived from LNs of $\mathrm{Ccr}^{-/-}$mice should not efficiently prime Th2 differentiation. To test this, we first verified that mediastinal LNs of $C \mathrm{Cr} 7^{-/-}$mice contain CD11 b ${ }^{\text {hi }}$ DCs, but almost no $\mathrm{CD} 103^{+} \mathrm{DCs}$ (Figure 4a and $\mathbf{b}$ ). We then compared the T-cell priming activity of total CD11 $\mathrm{c}^{+} \mathrm{DCs}$ recovered from $\mathrm{LNs}$ of OVA-instilled WT and $\mathrm{C} c r 7^{-/-}$mice. T cells cultured with the $\mathrm{C} c r 7^{-/-}$DCs produced high levels of IFN- $\gamma$, but very little IL-4 compared to T cells cultured with wild-type (WT) DCs (Figure 4c). Thus, CD $11 b^{\text {hi }}$ DCs from $C c r 7^{-/-}$LNs can effectively prime Th1 cell differentiation, but not Th2 differentiation. To confirm that the inability of LN DCs from $C \mathrm{Cr} 7^{-/-}$mice to prime Th2 differentiation was due to the absence of $\mathrm{CD} 103^{+}$ DCs and not to an intrinsic defect in $C \mathrm{Cr} 7^{-/-}$DCs, we studied T-cell priming by $\mathrm{CD} 103^{+}$DCs prepared from the lungs of $\mathrm{C} C r 7^{-/-}$mice. These DCs were as efficient, at Th2 priming, as their WT counterparts (Figure 4d). Thus, the inability of LN DCs from $\mathrm{Crr}^{-/-}$mice to promote Th2 differentiation is not due to an intrinsic requirement of CCR7, but rather to the selective absence of $\mathrm{CD} 103^{+}$DCs in mediastinal LNs of these animals.

\section{Allergic airway inflammation is impaired in mice lacking CD103+ DCs}

Having established that $\mathrm{CD} 103^{+}$DCs are required for ex vivo priming of Th2 responses, we next investigated if this DC subset is also required for priming allergic responses to inhaled allergens in vivo. We studied allergic responses in the recombinant inbred strain, BXH2/TyJ, which lack $\mathrm{CD}_{103}{ }^{+} \mathrm{DCs}$ in most non-lymphoid organs, including the lung, due to a point mutation in IFN regulatory factor 8 coding region. ${ }^{29,30}$ We first confirmed that $\mathrm{CD} 103^{+}$DCs are absent in the lungs of BXH2 

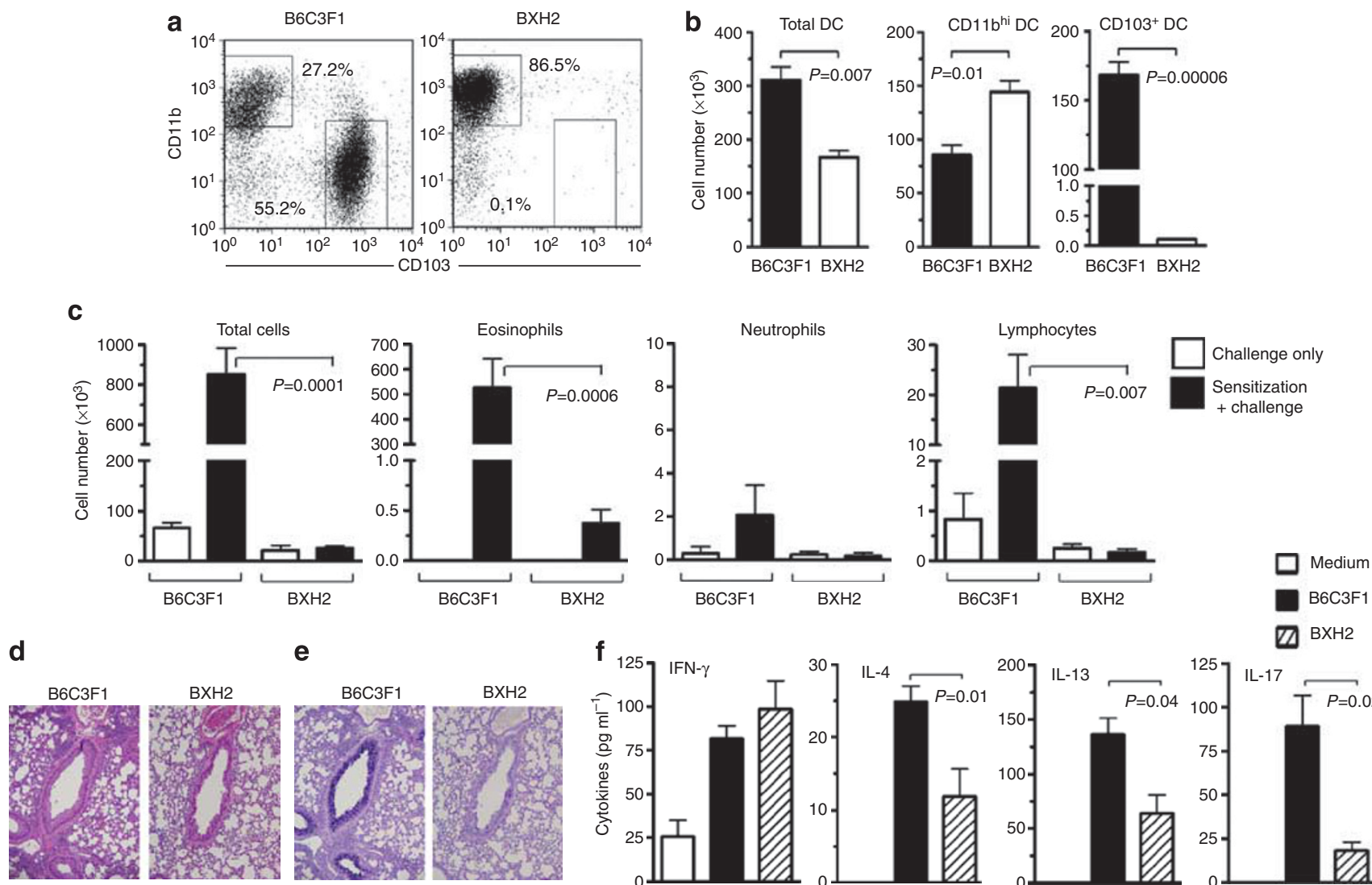

e
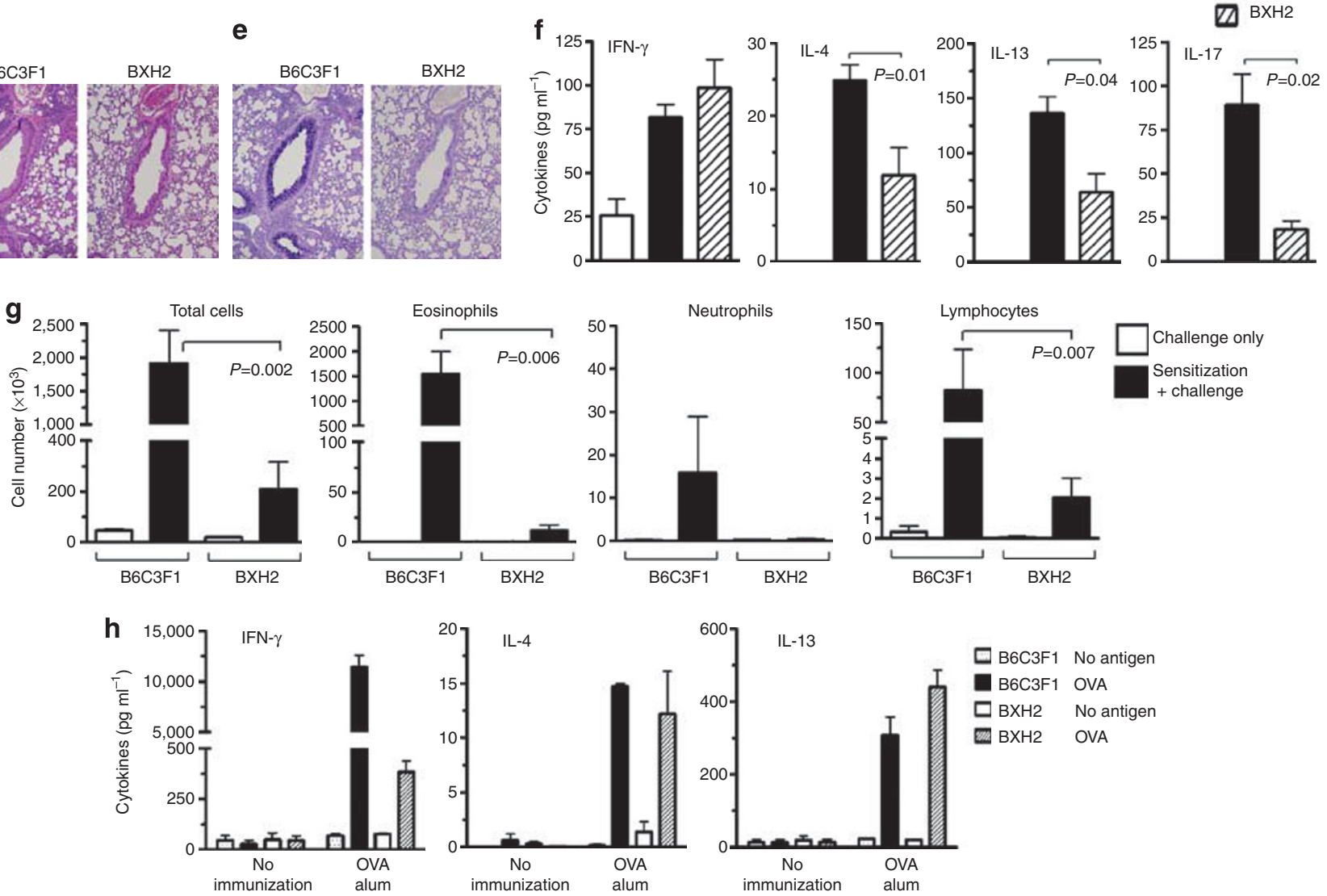

Figure 5 Impaired allergic airway inflammation in $\mathrm{CD}_{103^{+}}$dendritic cell (DC)-deficient BXH2 mice. (a, b) Analysis of CD11c ${ }^{\text {hi }}$ lung DCs from B6C3F1 and BXH2 mice. (a) Representative flow cytometry plots showing percentages of each DC subset. (b) Compiled data showing total cells for each subset ( $n=3)$. (c-f) Responses of B6C3F1 and BXH2 mice to sensitization and challenge with house dust extract (HDE; see METHODS). (c) Airway inflammation. Mean numbers \pm s.e.m. of the indicated leukocyte subsets in bronchoalveolar lavage fluid (BALF) are shown after HDE challenge of unsensitized (open columns) and sensitized mice (filled columns). $P$-values by Student's $t$-test $(n=3-7)$. (d) Hematoxylin and eosin (H\&E) staining of lung sections. (e) Airway mucus (dark purple), revealed by periodic acid-Schiff staining and Alcian Blue staining of lung sections. (f) Cytokine production. Left lung lobes were incubated for 2 days in culture medium containing HDE, and cytokines in the supernatants were measured by enzyme-linked immunosorbent assay (ELISA). (g) Allergic responses to cockroach antigen (CA) challenge. Mice were sensitized and challenged with CA (see METHODS) and the indicated cells in the BALF evaluated by differential staining. $P$-values by Student's $t$-test $(n=3-7)$. (h) Th2 responses in B6C3F1 and BXH2 mice following subcutaneous sensitization. Mice were immunized by foot-pad injections of ovalbumin (OVA)/alum, and cells from draining popliteal LNs cultured in the presence or absence of OVA. Cytokines in culture supernatants were analyzed by ELISA. Mean values \pm S.e.m. in triplicate assays are shown. Data represent one of the three independent experiments yielding similar results. IFN, interferon; IL, interleukin. 
mice (Figure 5a and $\mathbf{b}$ ), but present in the $\mathrm{B} 6 \mathrm{C} 3 \mathrm{~F} 1$ mice, which are derived from the same parental strains. To elicit allergic sensitization in vivo, we instilled OVA-LPS into the airways of mice. ${ }^{21-23}$ As expected, WT B6C3F1 mice sensitized in this way developed eosinophilic and neutrophilic airway inflammation on subsequent challenge with OVA (Supplementary Figure S5 online). However, similarly treated BXH2 mice failed to develop inflammation. To determine whether BXH2 mice are also refractory to sensitization to clinically relevant environmental allergens, we carried out experiments using extracts of common house dust. House dust contains both allergens and adjuvants, and when repeatedly instilled into the airway, HDEs induce multiple asthma-like responses, including airway inflammation. ${ }^{31} \mathrm{~B} 6 \mathrm{C} 3 \mathrm{~F} 1$ mice became sensitized to components of $\mathrm{HDE}$, as evidenced by the presence of inflammatory cells in bronchoalveolar lavage fluid following challenge of the mice with the same extract (Figure 5c). This inflammation resulted from adaptive immune responses to HDE rather than from innate immune responses, because very few cells were seen in bronchoalveolar lavage fluid of challenged mice that had not been previously sensitized with HDE. Unlike B6C3F1 mice, CD103 ${ }^{+}$DC-deficient BXH2 mice were not sensitized by HDE and failed to develop significant airway or interstitial lung inflammation on challenge (Figure 5c and d). $\mathrm{BXH} 2$ mice also had substantially fewer mucus-producing cells in the airway than B6C3F1 mice (Figure 5e) and had lower levels of IL-4, IL-13, and IL-17 in the lung (Figure 5f). Similar results were observed when mice were sensitized and challenged with CA (Figure 5g). These findings suggested that pulmonary $\mathrm{CD}_{103}{ }^{+} \mathrm{DCs}$ are required for allergic sensitization to inhaled allergens. To rule out the possibility that the reduced allergic pulmonary inflammation seen in $\mathrm{BXH} 2$ mice was due to a defect in cells other than $\mathrm{CD} 103^{+}$DCs, we tested the ability of BXH2 mice to develop Th2 responses following subcutaneous sensitization, which is mediated by multiple DC subsets. ${ }^{32}$ Analysis of responses in skin-draining LNs revealed that $\mathrm{T}$ cells from immunized BXH2 mice produced lower levels of IFN- $\gamma$ than did their counterparts from WT mice (Figure 5h), possibly because the IFN regulatory factor- 8 mutation leads to impaired production of IL-12 and IFN- $\alpha$ by APCs. ${ }^{33}$ However, production of IL- 4 and IL-13 were comparable in $\mathrm{BXH} 2$ and $\mathrm{B} 6 \mathrm{C} 3 \mathrm{~F} 1$ mice. The numbers of bone marrow eosinophils were also similar in the two strains (data not shown). Together, these data indicate that the reduced allergic response in $\mathrm{BXH} 2$ mice after sensitization through the airway was not due to a general impairment in Th2 responses or eosinophil development, but rather to the absence of $\mathrm{CD}_{103^{+}}$DCs in the lung and draining LNs.

\section{Differential expression of molecules by lung-resident DC subsets}

To investigate the mechanisms that might account for the priming of Th1 and Th2 differentiation by CD11 $\mathrm{b}^{\text {hi }}$ and $\mathrm{CD} 103^{+}$ lung DCs, respectively, we compared the expression of several candidate molecules. Differential expression of Notch ligands has been proposed to contribute to T-helper cell differentiation, with Jagged 1 and Jagged 2 promoting Th2 differentiation and
Delta-like 4 promoting Th1 differentiation. ${ }^{34}$ We found that Jag 1 expression was similar in the two DC subsets, whereas Jag 2 expression was higher in CD103 ${ }^{+}$DCs than CD11b ${ }^{\text {hi }}$ DCs (Supplementary Figure S6 online). In contrast, Dll 4 expression was slightly higher in CD11b $\mathrm{b}^{\text {hi }}$ DCs, although not statistically significant. Thus, differential expression of these Notch ligands by the two major lung DC subsets might contribute to their abilities to promote T-helper differentiation.

Analysis of cytokine production by DCs following their activation ex vivo revealed that CD11bi DCs had higher levels of IFN- $\gamma$ than did $\mathrm{CD}_{103}{ }^{+}$DCs (Supplementary Figure S7a and c-e online). However, IFN- $\gamma$-deficient CD11b ${ }^{\text {hi }}$ DCs did not acquire Th2-inducing ability (Supplementary Figure S8a online). As expected, neither CD11b ${ }^{\text {hi }}$ DCs nor $\mathrm{CD} 103^{+}$DCs produced detectable IL-4 (Supplementary Figure S7a online), and IL-4deficient $\mathrm{CD}_{103}{ }^{+}$DCs primed Th2 differentiation at least as efficiently as their WT counterparts (Supplementary Figure S8b online). $\mathrm{CD} 103^{+} \mathrm{DCs}$ also produced higher levels of IL-1 $\beta$, IL-2, IL-9, IL-10, and CCL11 than CD11b ${ }^{\text {hi }}$ DCs (Supplementary Figure S7 a and $\mathbf{b}$ online). However, IL-2-deficient and IL-9deficient $\mathrm{CD} 103^{+}$DCs primed Th2 differentiation as efficiently as their WT controls (Supplementary Figure S8c and $\mathbf{d}$ online). IL-10-deficient CD103+ DCs had a modest, but significant, reduction in their ability to induce IL-4 and IL-13 production by T cells compared with WT counterparts (Supplementary Figure S8e online and data not shown), suggesting that $\mathrm{CD}_{103^{+}}$ DC production of IL-10 contributes to Th2 induction.

Analysis of cell surface molecules revealed that most were displayed at similar levels on CD11b ${ }^{\text {hi }}$ and $\mathrm{CD} 103^{+}$DCs (Supplementary Figure S9a and $b$ online). These molecules included CD70 and OX40L, which are reported to promote Th1 and $\mathrm{Th} 2$ responses, respectively. ${ }^{35-37} \mathrm{CD} 103^{+}$DCs had slightly higher levels of CD86, which is associated with Th2 priming, ${ }^{38}$ whereas CD11b $b^{\text {hi }}$ DCs displayed higher levels of CD14 and Ly6C, which is associated with Th1-stimulating inflammatory DCs (Supplementary Figure S9b online). ${ }^{3,4,39} \mathrm{CD} 103^{+}$DCs also displayed higher levels of CD117/c-Kit, which is reported to participate in the priming of Th2 and Th17 responses. ${ }^{40}$ However, $\mathrm{CD}_{103}{ }^{+} \mathrm{DCs}$ from lungs of c-Kit mutant $W / W^{v}$ mice induced Th2 differentiation as efficiently as those from WT mice (Supplementary Figure S8f online).

\section{Selectivity of T-helper induction by lung-resident DCs is conferred by levels of antigen presentation}

In our analyses of cell surface molecule expression, we noticed that CD $11 b^{\text {hi }}$ DCs displayed slightly higher levels of MHC class II and much higher levels of the macrophage mannose receptor (Figure 6a). The latter molecule mediates uptake of several soluble antigens, including OVA. ${ }^{41}$ These observations suggested that CD $11 b^{\text {hi }}$ DCs might take up and present more antigen to T cells than do $\mathrm{CD}_{103}{ }^{+}$DCs. Using Alexa Fluor-647-labeled OVA, we confirmed that CD11 bi DCs take up higher amounts of OVA than do $\mathrm{CD} 103^{+}$DCs over a wide range of OVA concentrations (Figure $\mathbf{6 b}$ and $\mathbf{c}$ ). Because we had found that poly I:C conferred a Th1-inducing phenotype to $\mathrm{CD} 103^{+} \mathrm{DCs}$ (Supplementary Figure S4 online), we analyzed lung DCs after 
a
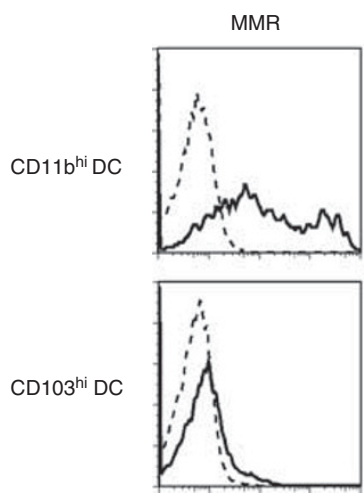

Fluorescence intensity

b

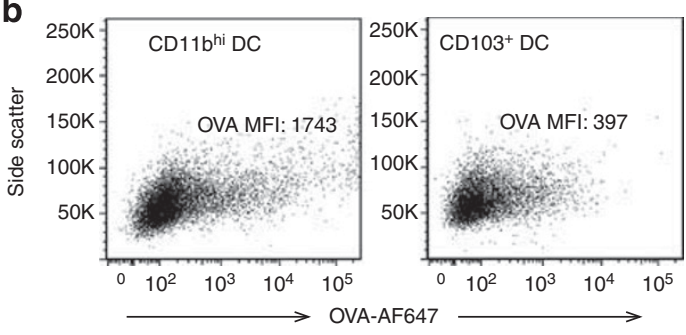

C

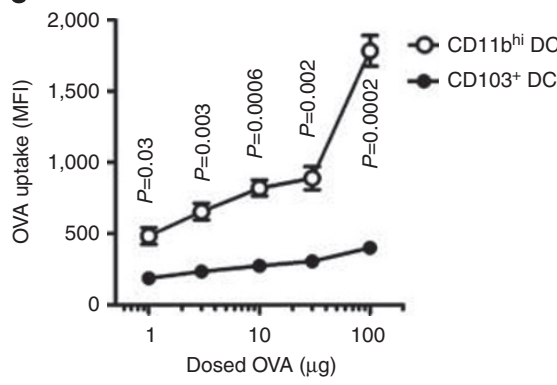

d
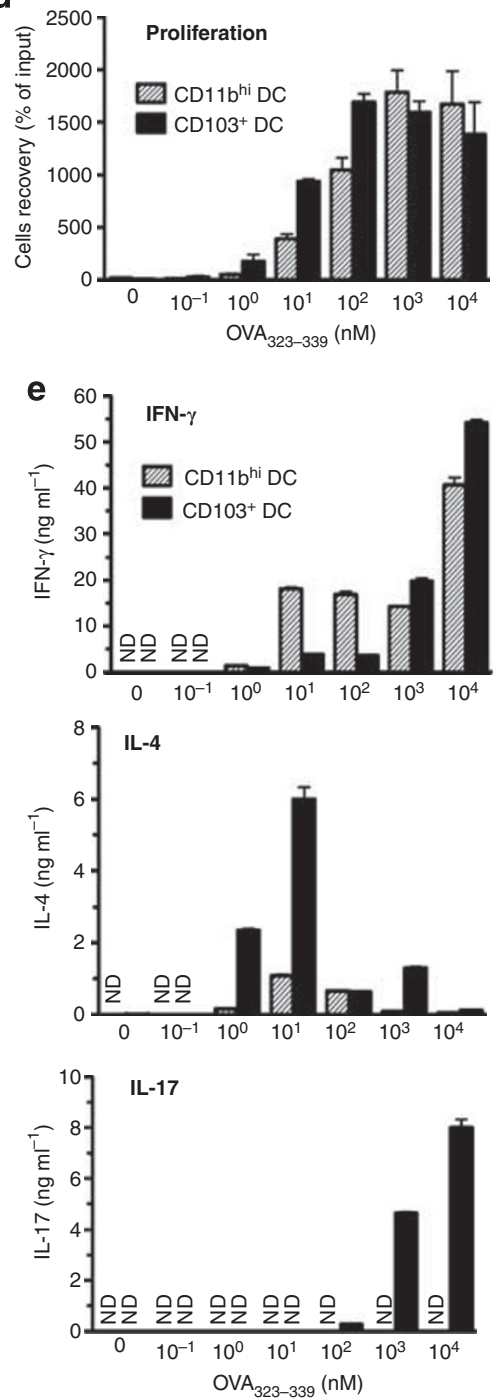

Figure 6 Effect of antigen uptake by lung dendritic cell (DC) subsets on T-cell differentiation. (a) Surface molecule display. Macrophage mannose receptor (MMR) and major histocompatibility complex (MHC) class II on lung DC subsets of untreated C57BL/6 mice were stained with specific antibodies (solid line) or with isotype control antibodies (dotted line). (b) Ovalbumin (OVA) uptake by DC subsets. Flow plots are shown for OVA-Alexa Fluor (AF)-647 fluorescence in CD11 bi and CD103+ lung-resident DCs at 24h after instillation of $100 \mu \mathrm{g}$ OVA-AF647 together with lipopolysaccharide (LPS). (c) OVA-AF647 uptake (mean fluorescence intensity, MFI) by the lung-resident DCs after instillation of various amounts of OVA-AF647. $P$-value by Student's $t$-test $(n=3)$. Results from one of the two similar experiments are shown. (d, e) Effect of peptide concentration on T-cell proliferation and cytokine production. CD11 $\mathrm{b}^{\text {hi }}$ and CD103+ lung-resident DCs were prepared from lungs of untreated C57BL/6 mice, loaded with the indicated amounts of $\mathrm{OVA}_{323-339}$ peptide ex vivo, and cultured with naive CD4+ OT-II T cells. Proliferation of T cells in cocultures (d) and cytokine production from $T$ cells measured by enzyme-linked immunosorbent assay following elicitation by anti-CD3 $\varepsilon$ and CD28 antibodies (e) are indicated. One of the two independent experiments yielding similar results is shown. IFN, interferon; IL, interleukin; ND, not detected.

airway instillation of this microbial product. Poly I:C instillation increased MHC class II and CD86 on both CD103+ DCs and CD11b ${ }^{\text {hi }}$ DCs. Poly I:C also increased the levels of OVA uptake by $\mathrm{CD} 103^{+}$DCs, but not by CD $11 b^{\text {hi }}$ DCs (Supplementary Figure $\mathbf{S 1 0}$ online). To determine whether the levels of antigen presentation impacted T-helper differentiation, $\mathrm{CD}_{103}{ }^{+}$and $\mathrm{CD} 11 \mathrm{~b}^{\text {hi }}$ DCs were sorted from the lungs of untreated mice and subsequently loaded ex vivo with various amounts of OVA peptide. Although both DC subsets induced proliferation of CD4 ${ }^{+}$ OT-II T cells in a manner dependent on peptide concentration, $\mathrm{CD}_{103}{ }^{+} \mathrm{DCs}$ were more potent at low concentrations of peptide (Figure 6d). CD11bi DCs primed Th1 differentiation at all concentrations of peptide, although this priming was stronger at higher concentrations of peptide (Figure 6e). However, $\mathrm{CD} 11 \mathrm{~b}^{\text {hi }} \mathrm{DCs}$ were unable to efficiently prime Th2 differentiation, regardless of the peptide concentration used. In contrast, $\mathrm{CD}_{103}{ }^{+}$DC priming of Th2 cells was highly dependent on peptide levels. At low concentrations of peptide, $\mathrm{CD} 103^{+}$DCs exclusively primed Th2 responses, whereas at high levels, these DCs primed both Th1 and Th17 differentiation. Taken together, the current data show that $C D 11 b^{\text {hi }}$ DCs selectively prime Th1 responses to OVA, whereas $\mathrm{CD} 103^{+}$DCs can prime either Th2 or Th1 and Th17 responses, depending on the strength of peptide presentation. 


\section{DISCUSSION}

Findings presented here suggest that at least for inhaled allergens, $\mathrm{CD} 103^{+}$DCs are the primary DC subset in the lung and draining LNs that prime Th2 responses, whereas CD11b ${ }^{\text {hi }}$ DCs prime Th1 responses. These findings are consistent with multiple studies showing that DCs are important for the induction of allergic responses. ${ }^{7,13,15,16}$ Although basophils have been reported to be sufficient for the induction of some allergic responses, ${ }^{9-12}$ subsequent reports have shown that these cells are dispensable for allergic sensitization to inhaled allergens. ${ }^{13-15}$ It is possible that allergic responses to inhaled allergens are more dependent on DCs and less dependent on basophils than are other Th2-mediated responses. Previous reports have suggested that CD11b ${ }^{\text {hi }}$ DCs are crucial for the development of allergic responses in airway. ${ }^{19,42}$ However, it was unclear from these studies if $\mathrm{CD} 11 \mathrm{~b}{ }^{\text {hi }}$ DCs are required for the induction of Th2 differentiation or for restimulation of existing memory Th2 cells. We have found that both major DC subsets can restimulate previously differentiated Th 2 cells, as measured by IL- 4 production (H. Nakano et al., unpublished observations). The ability of the $\mathrm{CD} 103^{+}$DCs to stimulate memory Th2 responses was also recently suggested in a model of LPS-induced exacerbations of asthma-like symptoms in mice. ${ }^{43}$ Thus, both major lung DC subsets appear to be capable of activating memory $\mathrm{T}$ cells.

We found that $\mathrm{CD}_{103}{ }^{+} \mathrm{DC}$-deficient $\mathrm{BXH} 2$ mice were refractory to allergic sensitization through the airway, despite having the ability to develop Th2 responses in skin-draining LNs after subcutaneous immunization. Another consequence of the IFN regulatory factor- 8 mutation in $\mathrm{BHX} 2$ mice is a reduction in IL-12 and type-I IFN production by DCs. ${ }^{33}$ However, those cytokines promote Th1 responses, not Th2 responses, and it seems unlikely that a reduction in these cytokines could account for the profoundly reduced allergic responses in $\mathrm{BXH} 2$ mice. The presence of both migratory and non-migratory DCs in LNs complicates interpretation of LN DC data. However, $\mathrm{CD} 103^{+}$ DCs prepared from the lung also primed Th2 responses more efficiently than did CD11b ${ }^{\text {hi }}$ DCs, suggesting that the differences in T-helper priming between these two DC subsets is not due solely to difference in their migratory capacities. We cannot formally exclude the possibility that CD $8 \alpha^{+}$DCs, which are lacking in BXH2 mice, ${ }^{33}$ contribute to allergic sensitization to inhaled allergens. However, CD $8 \alpha^{+}$DCs are very rare in the lung ${ }^{17,44}$ and they are reported to preferentially stimulate Th1-cell differentiation. ${ }^{45}$ Thus, a major involvement of CD8 $\alpha^{+}$DCs in the induction of allergic responses in vivo seems unlikely. Taken together, our data suggest that $\mathrm{CD} 103^{+} \mathrm{DCs}$ are the major DC subset for priming allergic responses to inhaled allergens.

The properties of lung CD103+ DCs that endow them with the ability to prime Th2 responses to inhaled antigens are not yet fully understood. We found that $\mathrm{CD}_{103^{+}}$DCs express high levels of the Notch ligand, Jagged 2, which has been associated with Th2 induction by DCs in vitro, ${ }^{34}$ However, a requirement of this gene for Th2 responses in vivo has been questioned, ${ }^{46}$ and it remains to be determined whether Jagged is required for allergic sensitization through the airway. The propensity of $\mathrm{CD} 103^{+} \mathrm{DCs}$ to take up relatively low levels of OVA in vivo might contribute to OVA-specific Th2 priming, because when forced to present high levels of exogenously added OVA peptide ex vivo, $\mathrm{CD} 103^{+} \mathrm{DCs}$ lost their ability to promote Th2 differentiation, and instead primed Th1 and Th17 differentiation. This observation is in agreement with previous reports showing that low levels of peptide presentation to $\mathrm{T}$ cells primes $\mathrm{Th} 2$ induction by upregulating GATA3 expression, which is critical for Th2 differentiation. ${ }^{47,48}$ Conversely, strong T-cell receptor stimulation suppresses GATA3 expression through activation of extracellular signal-regulated kinase. ${ }^{48}$ Although $\mathrm{CD} 103^{+}$DCs that acquired OVA in vivo exclusively primed Th2 differentiation of naive OT-II T cells, $\mathrm{CD} 103^{+}$DCs that acquired CA or HDM in vivo were able to prime Th1, Th2, and Th17 differentiation of polyclonal naive $\mathrm{CD} 4^{+} \mathrm{T}$ cells. OVA uptake by $\mathrm{CD} 103^{+} \mathrm{DCs}$ is likely limited by their low display levels of macrophage mannose receptor, whereas CA and HDM might be taken up by other C-type lectins that are more highly expressed in $\mathrm{CD}_{103}{ }^{+} \mathrm{DCs}$. Alternatively, microbial components present in the preparations of $\mathrm{HDM}$ and CA might confer $\mathrm{CD} 103^{+} \mathrm{DCs}$ with the capacity to promote Th1 and Th17 differentiation. This hypothesis is consistent with our finding that after poly I:C treatment, $\mathrm{CD} 103^{+}$ DCs displayed higher levels of MHC class II, increased OVA uptake and promoted Th1 differentiation. Importantly, however, CD1 $1 b^{\text {hi }}$ DCs failed to efficiently prime Th2 differentiation after in vivo uptake of OVA, CA or HDM, or after ex vivo loading of OVA peptide. Thus, inherent differences between these two DC subsets, in addition to uptake of antigen or antigen processing, must also contribute to their differences in T-cell priming.

The inefficient Th2 induction by CD $11 b^{\text {hi }}$ DCs, even when presenting very low levels of peptide, suggests that low strength of antigen presentation is not sufficient for priming Th2 responses and that $\mathrm{CD} 103^{+}$DCs must provide additional signals that stimulate Th2 differentiation. Although $\mathrm{CD} 103^{+}$DCs produced IL-2, IL-4, and IL-9, analysis of DCs from gene-targeted mice revealed that none of these cytokines are required for Th2 priming by this DC subset. CD $103^{+}$DCs also produced IL-10, and the partial reduction of Th2 inducing ability of $\mathrm{Il}-10^{-/-}$ $\mathrm{CD}_{103}{ }^{+} \mathrm{DCs}$ suggests that IL- 10 might contribute to Th2 induction. Although c-Kit is selectively expressed by $\mathrm{CD} 103^{+} \mathrm{DCs}$, $\mathrm{CD} 103^{+}$DCs from c-Kit mutant $W / W^{v}$ mouse lung could prime Th2 differentiation as efficiently as DCs from WT mice. IL-25, IL-33, and thymic stromal lymphopoietin (TSLP) have also been reported to promote Th2 differentiation, ${ }^{49-51}$ but these cytokines were undetectable in supernatants of $\mathrm{CD}_{103}{ }^{+} \mathrm{DCs}$ (data not shown), possibly because lung epithelia are the primary source of these cytokines. ${ }^{52}$ Thus, it remains to be determined whether cytokines other than IL-10 selectively produced by CD $103^{+}$ DCs can direct Th2 differentiation. However, the identification of these cells as the primary DC subset for initiating allergic responses to inhaled allergens should facilitate the identification of such molecules. A comprehensive comparison of genes that are differentially expressed in the two major lung DC subsets might yield novel candidate genes whose requirement for Th2 differentiation can be tested experimentally. The information gained from these studies might, in turn, reveal novel opportunities to prevent or mitigate the severity of allergic asthma. 


\section{METHODS}

Mice. B6C3F1, BALB/c, BXH2/TyJ, C57BL/6, Ccr7-/- (B6. 129P2Ccr $\left.7^{\text {tm1Dgen }} / \mathrm{J}\right)$, DO11.10 (C.CG-Tg(DO11.10)10Dlo/J), Ifng ${ }^{-/-}$ (B6.129S7-Ifng tm1Ts/J), Il2-/- (B6.129P2-Il2 tm1Hor /J), Il4-/-

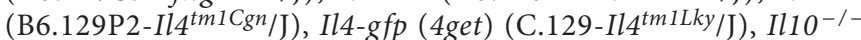

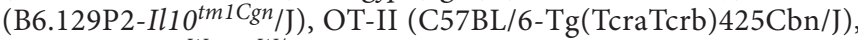
WBB6F1/J-Kit ${ }^{W} / \mathrm{Kit}^{W / v}$ and their WT controls WBB6F1/J- +/+ were purchased from Jackson Laboratories (Bar Harbor, ME). Rag2 ${ }^{-/-}$OT-II mice (B6.129S6-Rag2 $2^{\text {tm1Fwa }} \mathrm{Tg}$ (TcraTcrb)425Cbn) were obtained from Taconic Farms (Germantown, NY). Il4- $g f p^{+}$DO11.10 mice were generated by crossing Il4-gfp and DO11.10 mice. $I l-9^{-/-}$mice were provided by Simon Hogan (University of Cincinnati), with permission from Andrew Mackenzie (MRC, Cambridge, UK). All mice were housed in the specific pathogen-free animal facility at the National Institute of Environmental Health Sciences (NIEHS), and used between 6 and 12 weeks of age in accordance with guidelines provided by the Institutional Animal Care and Use Committee of the NIEHS.

Preparation of DCs. Lungs were extracted, minced, and digested with Liberase TM $\left(100 \mu \mathrm{g} \mathrm{ml}^{-1}\right.$; Roche, Indianapolis, IN), together with collagenase XI $\left(250 \mu \mathrm{g} \mathrm{ml}^{-1}\right)$, hyaluronidase $1 \mathrm{a}\left(1 \mathrm{mg} \mathrm{ml}^{-1}\right)$, and DNase I $\left(200 \mu \mathrm{g} \mathrm{ml}^{-1}\right.$; Sigma, St Louis, MO) for $1 \mathrm{~h}$ at $37^{\circ} \mathrm{C}$. Minced mediastinal LNs were digested with the same enzymes for $30 \mathrm{~min}$. In some experiments, lung tissues were digested with collagenase $\mathrm{D}\left(1 \mathrm{mg} \mathrm{ml}^{-1}\right)$ (Roche) and DNase I $\left(200 \mu \mathrm{g} \mathrm{ml}^{-1}\right)$. The reaction was stopped by the addition of EDTA (20 mM final concentration). A single-cell suspension was prepared by sieving the digested tissue through a $70 \mu \mathrm{m}$ nylon strainer (BD Biosciences, Bedford, MA). DCs were enriched by discontinuous phase-density centrifugation with $16 \%$ Nycodenz (Accurate Chemical, Westbury, NY), and then washed with phosphate-buffered saline containing $0.5 \%$ bovine serum albumin and $2 \mathrm{mM}$ EDTA. DC numbers per lung were calculated based on the total number of recovered cells and the percentages of DCs in those preparations. Total CD11 $c^{\text {hi }}$ DCs or DC subsets were purified by sorting on a fluorescence-activated cell sorting Vantage or fluorescence-activated cell sorting ARIA-II flow cytometer (BD Biosciences). Purity was consistently $>98 \%$. Cell morphologies were assessed by light microscopy following centrifugation onto glass slides. Antigens were delivered to the airway by oropharyngeal aspiration, and DCs harvested 16 or $24 \mathrm{~h}$ later. The following antigens were instilled in a total volume of $50 \mu \mathrm{l}$ phosphate-buffered saline; $100 \mu \mathrm{g}$ endotoxin-free OVA (Profos AG, Regensburg, Germany); $10 \mu \mathrm{g}$ cockroach antigens (Greer, Lenoir, NC); and $10 \mu \mathrm{g}$ house dust mite (Greer). LPS was removed from CA using ProteoSpin endotoxin removal kit (Norgen Biotek, Thorold, ON, Canada). Unless stated otherwise, OVA was delivered to the airways together with $10 \mathrm{pg}$ LPS (Sigma). In some experiments, $1 \mu \mathrm{g}$ poly I:C (Invivogen, San Diego, CA) was used as the adjuvant. For allergen tracking experiments, OVA, CA, and HDM were labeled with Alexa Fluor-647 (Invitrogen, Carlsbad, CA).

Flow cytometric analysis. Cells were diluted to $2 \times 10^{6} / 100 \mu \mathrm{l}$, and incubated with a nonspecific binding blocking reagent cocktail of anti-mouse CD16/CD32 (2.4G2), normal mouse, and normal rat serum (Jackson ImmunoResearch, West Grove, PA) for $5 \mathrm{~min}$. For staining of surface antigens, cells were incubated with fluorochrome (Allophycocyanin (APC), APC-Alexa Fluor-750, APC-Cy7, Alexa Fluor-488, Alexa Fluor-647, eFluor-450, fluorescein isothiocyanate, PerCP-Cy5.5, phycoerythrin (PE), PE-Texas Red) or biotin-conjugated antibodies against mouse CD4 (RM4-5 and GK1.5), CD8 $\alpha$ (53-6.7), CD11b (M1/70), CD11c (N418 and HL3), CD14 (Sa2-8), CD19 (605), CD40 (Ic10), CD44 (IM7), CD45.2 (104), CD45RB (C363.16A), CD80 (16-10A1), CD70 (FR70), CD83 (Michel-19), CD86 (GL1), CD103 (M290), CD115 (AFS98), CD117/c-Kit (2B8), F4/80 (BM8), Ly6C (AL-21), MHC class II (AFb.120), macrophage mannose receptor (MR5D3), OX40L (RH134L), and PD-L1 (MIH5; BD Biosciences, BioLegend, and eBioscience, San Diego, CA). Dead cells stained with 7 -amino-actinomycin D (eBioscience) were excluded from the analysis.
For intracellular cytokine analyses, cells were fixed and permeabilized with a kit (eBioscience), then stained with the following antibodies, IFN- $\gamma$ (XMG1.2), IL-2 (JES6-5H4), IL-4 (11B11), IL-9 (RM9A4) and IL-13 (eBio13A; BD Biosciences and eBioscience). Stained cells were analyzed on a fluorescence-activated cell sorting LSRII flow cytometer (BD Biosciences). Data from these studies were analyzed using fluorescence-activated cell sorting Diva (BD Biosciences) and FlowJo software (Treestar, Ashland, OR). Only single cells were analyzed.

Coculture of naive T cells with DCs. Naive $\mathrm{CD} 4^{+} \mathrm{T}$ cells were prepared from pools of LNs and spleens of C57BL/6, DO11.10, Il4-gfp DO11.10, OT-II or Rag2 ${ }^{-/-}$OT-II mice by magnetic bead-based cell sorting system (Miltenyi, Bergisch Gladbach, Germany) using an antibody cocktail containing anti-mouse CD $8 \alpha, \mathrm{CD} 11 b, \mathrm{CD} 11 \mathrm{c}, \mathrm{CD} 16 / 32$, CD19, CD25, CD44, B220, CD49b, I-A, and Ly6C/G. The purified cells were greater than $98 \% \mathrm{CD}^{+} \mathrm{T}$ cells, with less than $1 \%$ comprised of CD45RB ${ }^{\text {lo }}$ CD $44^{\text {hi }}$ memory cells (Supplementary Figure S11 online). T-cell receptor transgenic T cells $\left(1 \times 10^{5}\right.$ per well) or C57BL/6 T cells $\left(5 \times 10^{5}\right.$ per well $)$ were cultured in a $5 \% \mathrm{CO}_{2}$ incubator for 5 days with DCs $\left(5 \times 10^{4}\right.$ per well) purified from LNs or lungs in $200 \mu$ Iscove's modified Dulbecco's medium containing $10 \%$ fetal bovine serum (FBS; certified, Invitrogen), $50 \mu \mathrm{M} \beta$-mercaptoethanol, penicillin and streptomycin in a 96-well $\mathrm{U}$-bottom plate (BD Biosciences). In some experiments, various concentrations of OVA $323-339$ peptides (New England Peptide, Gardner, MA) were added to the culture. Following primary cultures, T-cell responses were elicited by incubation of T cells $\left(1 \times 10^{5}\right.$ per well $)$ for $24 \mathrm{~h}$ in a 96-well flat bottom plate coated with antibodies to CD3 $\varepsilon\left(1 \mu \mathrm{g} \mathrm{ml}^{-1}\right)$ and CD28 (5 $\mathrm{g} \mathrm{ml}^{-1}$; eBioscience).

Analyses of proliferation and cytokine production by T cells. After coculture of T cells and DCs, viable lymphocytes were counted by the Trypan blue exclusion test. T-cell recovery was calculated as percent of input. In some experiments, $\mathrm{CD} 4^{+} \mathrm{T}$ cells from OT-II mice were labeled with $3 \mu \mathrm{m} \mathrm{CFSE} \mathrm{(Invitrogen)} \mathrm{for} 10 \mathrm{~min}$ at $37^{\circ} \mathrm{C}$. CD $4^{+} \mathrm{CFSE}^{+}$cells were analyzed 2 or 5 days after coculture with lung DCs by flow cytometry, and proliferation of T cells was inferred from lower CFSE signal in comparison with unstimulated $\mathrm{T}$ cells. For analysis of cytokine production from T cells, cells were plated at $1 \times 10^{6}$ cells per $200 \mu$ l of complete RPMI containing $10 \% \mathrm{FBS}, 50 \mathrm{ng} \mathrm{ml}^{-1}$ phorbol myristate acetate and $500 \mathrm{ng} \mathrm{ml}^{-1}$ ionomycin (Sigma). The cells were incubated for $4 \mathrm{~h}$, with GolgiStop (BD Biosciences) added for the last $3 \mathrm{~h}$. After washing, intracellular cytokines in $\mathrm{CD}^{+} \mathrm{T}$ cells were analyzed by flow cytometry. Cytokines in supernatants of these cultures were measured by enzyme-linked immunosorbent assay using specific antibodies against IFN- $\gamma$ (R4-6A2 and XMG1.2), IL-4 (11B11 and BVD6-24G), IL-5 (TRFK5 and TRFK4), IL-13 (eBio13A and eBio1316H), and IL-17 (TC11-18H10 and TC11-8H4; BD Biosciences and eBioscience).

Analysis of cytokine production by DC subsets. DCs sorted by flow cytometry were plated at $1 \times 10^{5}$ cells per $200 \mu$ l of complete RPMI containing $10 \% \mathrm{FBS}, 50 \mathrm{ng} \mathrm{ml}^{-1}$ phorbol myristate acetate, and $500 \mathrm{ng} \mathrm{ml}^{-1}$ ionomycin. Supernatants were collected $24 \mathrm{~h}$ later, and analyzed for cytokines by multiplex analysis (BioRad, Hercules, CA). For intracellular staining of cytokines, DCs were incubated with or without phorbol myristate acetate and ionomycin for $16 \mathrm{~h}$, and then analyzed by flow cytometry.

Allergic airway inflammation. Mice were sensitized by oropharyngeal aspiration of allergen on days 0 and 7, challenged with the same allergen on 4 consecutive days (14 to 17) and analyzed on day 20. All oropharyngeal aspirations were done in a total volume of $50 \mu \mathrm{l}$, using phosphate-buffered saline as the carrier. For OVA sensitizations, $100 \mu \mathrm{g}$ endotoxin-free OVA supplemented with $10 \mathrm{pg}$ LPS was used. These animals were challenged for $30 \mathrm{~min}$ on 4 consecutive days with an aerosol of 1\% OVA (Sigma) in phosphate-buffered saline and harvested 3 days later. For HDE sensitizations, $20 \mu$ l of $\operatorname{HDE}^{53}$ was used on days 0 and 7 , and the mice challenged on 4 consecutive days by instillation of $5 \mu$ of 
the same HDE. Ten $\mu$ g of endotoxin-free CA, supplemented with $20 \mu \mathrm{l}$ HDE was used to sensitize mice, and they were challenged on 4 consecutive days by instillations of $5 \mu \mathrm{g}$ of CA (no HDE). Whole-lung lavage was performed and cell differentials determined as previously described. ${ }^{23}$ Left lung lobes were fixed in $10 \%$ formalin and embedded in paraffin. Longitudinal sections 5-7 $\mu \mathrm{m}$ thick were stained with hematoxylin and eosin (H\&E), or Alcian Blue and periodic acid-Schiff, and analyzed by light microscopy. The right lobes of the lung were incubated in $1 \mathrm{ml} \mathrm{com-}$ plete RPMI1640, supplemented with $10 \% \mathrm{FBS}$ and $5 \mu \mathrm{ml}^{-1} \mathrm{HDE}$ for 2 days in a $5 \% \mathrm{CO}_{2}$ incubator, and cytokines in the supernatant were measured by enzyme-linked immunosorbent assay.

Cytokine production from skin-draining LNs. Mice were immunized by subcutaneous injection of $20 \mu \mathrm{g}$ OVA absorbed in alum (Thermo, Rockford, IL) in total volume of $20 \mu$ into hind footpad. Nine days later, popliteal LNs were excised, and LN cells were cultured at $1 \times 10^{6}$ cells per $200 \mu \mathrm{l}$ of complete RPMI containing $10 \%$ FBS in a 96 -well plate in the presence or absence of $1 \mathrm{mg} \mathrm{ml}^{-1}$ OVA. Supernatants were collected 3 days later, and analyzed for cytokines by enzyme-linked immunosorbent assay.

Real-time PCR. DCs were prepared from the lung $16 \mathrm{~h}$ after oropharyngeal aspiration of $100 \mu \mathrm{g}$ OVA and $10 \mathrm{pg}$ LPS. Total RNA from sorted DCs was prepared using RNeasy columns (Qiagen, Valencia, CA) and converted to complementary DNA using oligo dT primers and SuperScript III First Strand kit (Invitrogen). PCR amplification was performed using TaqMan primers and probes (Applied Biosystems, Carlsbad, CA) for Jagged 1 (assay ID: Mm00496902_m1), Jagged 2 (assay ID: Mm01325629_ m1), Delta-like 4 (assay ID: Mm00444619_m1), and Gapdh (assay ID: Mm99999915_g1) with TaqMan PCR Master Mix (Applied Biosystems) and Mx3000P QPCR system (Agilent Technologies, Santa Clara, CA). The relative expression level of each gene was determined according to the manufacture's instruction, and normalized to Gapdh expression.

Statistics. Data are expressed as mean \pm s.e.m. Statistical differences between groups were calculated using a two-tailed Student's $t$-test, unless otherwise specified. $P$-values are indicated in Figures.

SUPPLEMENTARY MATERIAL is linked to the online version of the paper at http://www.nature.com/mi

\section{ACKNOWLEDGMENTS}

We thank Maria Sifre and Carl Bortner for help with flow cytometry; Laura Miller, Ligon Perrow, Herman Price, and Dan Morgan for support with animal experiments; Andrew McKenzie (Medical Research Council, UK and Simon Hogan (University of Cincinnati) for providing IL-9-deficient mice; Brian Kelsall (NIH/NIAID) for advice on DC preparation; Jim Aloor for advice on LPS removal; and Michael Fessler (NIEHS) and Cheolho Cheong (Rockefeller University) for critical reading of the manuscript. This work was supported by the Intramural Research Program of the National Institutes of Health (NIH) and the NIEHS.

\section{DISCLOSURE}

The authors declared no conflict of interest.

\section{(c) 2012 Society for Mucosal Immunology}

\section{REFERENCES}

1. Pulendran, B., Tang, H. \& Manicassamy, S. Programming dendritic cells to induce $\mathrm{T}(\mathrm{H}) 2$ and tolerogenic responses. Nat. Immunol. 11, 647-655 (2010).

2. Zhou, L., Chong, M.M. \& Littman, D.R. Plasticity of CD4+ T cell lineage differentiation. Immunity 30, 646-655 (2009).

3. Leon, B., Lopez-Bravo, M. \& Ardavin, C. Monocyte-derived dendritic cells formed at the infection site control the induction of protective Thelper 1 responses against Leishmania. Immunity 26, 519-531 (2007).

4. Nakano, H. et al. Blood-derived inflammatory dendritic cells in lymph nodes stimulate acute Thelper type 1 immune responses. Nat. Immunol. 10, 394-402 (2009).
5. Dong, C. TH17 cells in development: an updated view of their molecular identity and genetic programming. Nat. Rev. Immunol. 8, 337-348 (2008).

6. Coombes, J.L. et al. A functionally specialized population of mucosal CD103+ DCs induces Foxp3+ regulatory T cells via a TGF-beta and retinoic acid-dependent mechanism. J. Exp. Med. 204, 1757-1764 (2007).

7. Lambrecht, B.N. \& Hammad, H. Biology of lung dendritic cells at the origin of asthma. Immunity 31, 412-424 (2009).

8. Paul, W.E. \& Zhu, J. How are $T(H) 2$-type immune responses initiated and amplified? Nat. Rev. Immunol. 10, 225-235 (2010).

9. Perrigoue, J.G. et al. MHC class II-dependent basophil-CD4+ T cell interactions promote $\mathrm{T}(\mathrm{H}) 2$ cytokine-dependent immunity. Nat. Immunol. 10, 697-705 (2009).

10. Sokol, C.L., Barton, G.M., Farr, A.G. \& Medzhitov, R. A mechanism for the initiation of allergen-induced Thelper type 2 responses. Nat. Immunol. 9, 310-318 (2007).

11. Sokol, C.L. et al. Basophils function as antigen-presenting cells for an allergen-induced Thelper type 2 response. Nat. Immunol. 10, 713-720 (2009).

12. Yoshimoto, $T$. et al. Basophils contribute to $T(H) 2-\lg E$ responses in vivo via $\mathrm{IL}-4$ production and presentation of peptide-MHC class II complexes to CD4+ T cells. Nat. Immunol. 10, 706-712 (2009).

13. Ohnmacht, C. et al. Basophils orchestrate chronic allergic dermatitis and protective immunity against helminths. Immunity 33, 364-374 (2010).

14. Sullivan, B.M. et al. Genetic analysis of basophil function in vivo. Nat. Immunol. 12, 527-535.

15. Hammad, H. et al. Inflammatory dendritic cells - not basophils - are necessary and sufficient for induction of Th2 immunity to inhaled house dust mite allergen. J. Exp. Med. 207, 2097-2111 (2010).

16. Phythian-Adams, A.T. et al. CD11c depletion severely disrupts Th2 induction and development in vivo. J. Exp. Med. 207, 2089-2096 (2010).

17. Sung, S.S. et al. A major lung CD103 (alphaE)-beta7 integrin-positive epithelial dendritic cell population expressing Langerin and tight junction proteins. J. Immunol. 176, 2161-2172 (2006).

18. Beaty, S.R., Rose, C.E. Jr. \& Sung, S.S. Diverse and potent chemokine production by lung CD11bhigh dendritic cells in homeostasis and in allergic lung inflammation. J. Immunol. 178, 1882-1895 (2007).

19. Raymond, M. et al. Selective control of SIRP-alpha-positive airway dendritic cell trafficking through CD47 is critical for the development of $\mathrm{T}(\mathrm{H}) 2$-mediated allergic inflammation. J. Allergy Clin. Immunol. 124, 1333-1342 (2009).

20. Jahnsen, F.L. et al. Accelerated antigen sampling and transport by airway mucosal dendritic cells following inhalation of a bacterial stimulus. J. Immunol. 177, 5861-5867 (2006).

21. Eisenbarth, S.C. et al. Lipopolysaccharide-enhanced, toll-like receptor 4dependent T helper cell type 2 responses to inhaled antigen. J. Exp. Med. 196, 1645-1651 (2002).

22. Piggott, D.A. et al. MyD88-dependent induction of allergic Th2 responses to intranasal antigen. J. Clin. Invest. 115, 459-467 (2005).

23. Wilson, R.H. et al. Allergic sensitization through the airway primes Th17dependent neutrophilia and airway hyperresponsiveness. Am. J. Respir. Crit. Care Med. 180, 720-730 (2009).

24. Vermaelen, K. \& Pauwels, R. Accurate and simple discrimination of mouse pulmonary dendritic cell and macrophage populations by flow cytometry: methodology and new insights. Cytometry A 61, 170-177 (2004).

25. Jakubzick, C., Helft, J., Kaplan, T.J. \& Randolph, G.J. Optimization of methods to study pulmonary dendritic cell migration reveals distinct capacities of DC subsets to acquire soluble versus particulate antigen. J. Immunol. Methods 337, 121-131 (2008).

26. Kamogawa, Y., Minasi, L.A., Carding, S.R., Bottomly, K. \& Flavell, R.A. The relationship of IL-4- and IFN gamma-producing T cells studied by lineage ablation of IL-4-producing cells. Cell 75, 985-995 (1993).

27. GeurtsvanKessel, C.H. et al. Clearance of influenza virus from the lung depends on migratory langerin+CD11b- but not plasmacytoid dendritic cells. J. Exp. Med. 205, 1621-1634 (2008).

28. Hintzen, G. et al. Induction of tolerance to innocuous inhaled antigen relies on a CCR7-dependent dendritic cell-mediated antigen transport to the bronchial lymph node. J. Immunol. 177, 7346-7354 (2006).

29. Ginhoux, F. et al. The origin and development of nonlymphoid tissue CD103+ DCs. J. Exp. Med. 206, 3115-3130 (2009).

30. Edelson, B.T. et al. Peripheral CD103+ dendritic cells form a unified subset developmentally related to CD8alpha+ conventional dendritic cells. J. Exp. Med. 207, 823-836 (2010). 
31. Batzer, G. et al. Using house dust extracts to understand the immunostimulatory activities of living environments. Immunobiology 212, 491-498 (2007).

32. Oyoshi, M.K., Larson, R.P., Ziegler, S.F. \& Geha, R.S. Mechanical injury polarizes skin dendritic cells to elicit a $\mathrm{T}(\mathrm{H}) 2$ response by inducing cutaneous thymic stromal lymphopoietin expression. J. Allergy Clin. Immunol. 126, 976-984, 984 e971-975 (2010).

33. Tailor, P., Tamura, T., Morse, H.C. 3rd \& Ozato, K. The BXH2 mutation in IRF8 differentially impairs dendritic cell subset development in the mouse. Blood 111, 1942-1945 (2008).

34. Amsen, D. et al. Instruction of distinct CD4T helper cell fates by different notch ligands on antigen-presenting cells. Cell 117, 515-526 (2004).

35. Akiba, H. et al. Critical contribution of OX40 ligand to Thelper cell type 2 differentiation in experimental leishmaniasis. J. Exp. Med. 191, 375-380 (2000).

36. Murata, K. et al. Impairment of antigen-presenting cell function in mice lacking expression of OX40 ligand. J. Exp. Med. 191, 365-374 (2000).

37. Soares, H. et al. A subset of dendritic cells induces CD4+ T cells to produce IFN-gamma by an IL-12-independent but CD70-dependent mechanism in vivo. J. Exp. Med. 204, 1095-1106 (2007).

38. Kuchroo, V.K. et al. B7-1 and B7-2 costimulatory molecules activate differentially the Th1/Th2 developmental pathways: application to autoimmune disease therapy. Cell 80, 707-718 (1995).

39. Cheong, C. et al. Microbial stimulation fully differentiates monocytes to DC-SIGN/CD209(+) dendritic cells for immune T cell areas. Cell 143, 416-429 (2010).

40. Krishnamoorthy, N. et al. Activation of c-Kit in dendritic cells regulates T helper cell differentiation and allergic asthma. Nat. Med. 14, 565-573 (2008).

41. Burgdorf, S., Lukacs-Kornek, V. \& Kurts, C. The mannose receptor mediates uptake of soluble but not of cell-associated antigen for crosspresentation. J. Immunol. 176, 6770-6776 (2006).
42. Medoff, B.D. et al. CD11b+ myeloid cells are the key mediators of Th2 cell homing into the airway in allergic inflammation. J. Immunol. 182, 623-635 (2009).

43. Ortiz-Stern, A. et al. Langerin(+) dendritic cells are responsible for LPSinduced reactivation of allergen-specific Th2 responses in postasthmatic mice. Mucosal Immunol. 4, 343-353 (2010).

44. Ballesteros-Tato, A., Leon, B., Lund, F.E. \& Randall, T.D. Temporal changes in dendritic cell subsets ${ }^{\star}$ cross-priming and costimulation via CD70 control CD8(+) T cell responses to influenza. Nat. Immunol. 11, 216-224 (2010).

45. Pulendran, B., Banchereau, J., Maraskovsky, E. \& Maliszewski, C. Modulating the immune response with dendritic cells and their growth factors. Trends Immunol. 22, 41-47 (2001).

46. Worsley, A.G. et al. Dendritic cell expression of the Notch ligand jagged2 is not essential for Th2 response induction in vivo. Eur. J. Immunol. 38, 1043-1049 (2008).

47. lezzi, G. et al. CD40-CD40L cross-talk integrates strong antigenic signals and microbial stimuli to induce development of IL-17-producing CD4+ T cells. Proc. Natl. Acad. Sci. USA 106, 876-881 (2009).

48. Yamane, H., Zhu, J. \& Paul, W.E. Independent roles for IL-2 and GATA-3 in stimulating naive CD4+ T cells to generate a Th2-inducing cytokine environment. J. Exp. Med. 202, 793-804 (2005).

49. Angkasekwinai, P. et al. Interleukin 25 promotes the initiation of proallergic type 2 responses. J. Exp. Med. 204, 1509-1517 (2007).

50. Schmitz, J. et al. IL-33, an interleukin-1-like cytokine that signals via the IL-1 receptor-related protein ST2 and induces T helper type 2-associated cytokines. Immunity 23, 479-490 (2005).

51. Soumelis, V. et al. Human epithelial cells trigger dendritic cell mediated allergic inflammation by producing TSLP. Nat. Immunol. 3, 673-680 (2002).

52. Wang, Y.H. \& Liu, Y.J. Thymic stromal lymphopoietin, OX40-ligand, and interleukin-25 in allergic responses. Clin. Exp. Allergy 39, 798-806 (2009).

53. Ng, N., Lam, D., Paulus, P., Batzer, G. \& Horner, A.A. House dust extracts have both TH2 adjuvant and tolerogenic activities. J. Allergy Clin. Immunol. 117, 1074-1081 (2006). 